\title{
Applying length-based assessment methods to fishery resources in the Bay of Biscay and Iberian Coast ecoregion: stock status and parameter sensitivity
}

\author{
Marta Cousido-Rocha ${ }^{1, *}$, Santiago Cerviño ${ }^{1}$, Alexandre Alonso-Fernández ${ }^{2}$, Juan Gil ${ }^{3}$, Isabel \\ González Herraiz ${ }^{4}$, Margarita María Rincón ${ }^{3}$, Fernando Ramos ${ }^{3}$, Cristina Rodríguez-Cabello ${ }^{5}$, Paz \\ Sampedro $^{4}$, Yolanda Vila ${ }^{3}$, Maria Grazia Pennino ${ }^{1}$
}

${ }^{1}$ Instituto Español de Oceanografía (IEO, CSIC). Centro Oceanográfico de Vigo. Subida a Radio Faro 50-52, 36390 Vigo, Pontevedra, Spain.

${ }^{2}$ Instituto de Investigaciones Marinas (IIM-CSIC), Eduardo Cabello 6, 36208 Vigo, Pontevedra, Spain.

3 Instituto Español de Oceanografía (IEO, CSIC). Centro Oceanográfico de Cádiz. Muelle de Levante s/n, Puerto Pesquero, 11006 Cádiz, Spain.

${ }^{4}$ Instituto Español de Oceanografía (IEO, CSIC). Centro Oceanográfico de A Coruña. Paseo Marítimo Alcalde Francisco Vázquez 10, 15001 A Coruña, Spain.

${ }^{5}$ Instituto Español de Oceanografía (IEO, CSIC). Centro Oceanográfico de Santander. Promontorio San Martín s/n. 39004 Santander. Spain

* Corresponding author.

E-mail address: marta.edu21@gmail.com

\begin{abstract}
Length-based methods have been widely applied to estimate biological parameters and understand the dynamics of marine resource populations within data-limited stocks. However, to date few studies have tested the sensitivity of parameters in length-based methods examining stocks with different traits and fishery contexts. In the Bay of Biscay and the Iberian Coast ecoregion, SE Europe (International Council for the Exploration of the Sea - ICES, Divisions 8 and 9a), many commercial resources are considered data-limited, and either little is known about their fisheries stock statuses or gaps remain in currently available assessments. Therefore, this study focuses on two of the most used length-based methods, which ICES considers to be the most appropriate to evaluate data-limited stocks, namely length-based indicators (LBI) and the length-based spawning potential ratio (LBSPR). Both methods have been applied to assess the stock statuses of various relevant species in the study area, such as: the small-spotted catshark (Scyliorhinus canicula), European anchovy (Engraulis encrasicolus), blackspot seabream (Pagellus bogaraveo), pouting (Trisopterus luscus), pollack (Pollachius pollachius), and Norway lobster (Nephrops norvegicus). For each stock, model results were compared with available knowledge on their current status. Furthermore, this paper discusses whether unexpected results are related to violations of the main model assumptions
\end{abstract}


43 (constant total mortality and recruitment, and logistic selectivity) or to a lack of representativeness of stock length composition. A sensitivity analysis was conducted on the two most important input parameters: $\mathrm{L}_{\infty}$ (von Bertalanffy asymptotic average maximum body size) and $\mathrm{M} / \mathrm{k}$ (ratio of natural mortality to von Bertalanffy growth rate). This analysis concluded that the variation/misspecification of both parameters $\left(\mathrm{M} / \mathrm{k}\right.$ and $\left.\mathrm{L}_{\infty}\right)$ had a considerable impact on the results given by both methods,

and that this effect is more significant in the case of the $\mathrm{L}_{\infty}$ parameter, thus highlighting the importance of its accuracy in a given assessment. Furthermore, the sensitivity analysis indicated that, among the LBI and LBSPR indicators, the least robust indicator was the LBI $\mathrm{P}_{\text {mega }}$ indicator. The remaining LBI method indicators can be considered more robust than the LBSPR indicators when there is uncertainty in the life history input parameters $\left(\mathrm{M} / \mathrm{k}\right.$ and $\left.\mathrm{L}_{\infty}\right)$. Among LBSPR indicators, SPR is more affected than F/M (relative fishing mortality) by the variation/misspecification of parameter $\mathrm{L}_{\infty}$, whereas under the variation of $\mathrm{M} / \mathrm{k}$ both indicators perform similarly. However, it is important to consider that LBI indicators are very rough measures of stock statuses, whereas LBSPR measures describe stock statuses more explicitly. Thus, both measures can be used together to obtain more precision in estimating stock status. Nevertheless, when critical parameters are uncertain (e.g., $\mathrm{L}_{\infty}$ ) and the results of both methods contradict one another, LBI method indicators, with the exception of $\mathrm{P}_{\text {mega, }}$ are more trustworthy than LBSPR indicators. marine capture in 2018 (FAO, 2020). To effectively manage exploited fish stocks biological and harvest information is needed to assess stock biomass (or abundance) and fishing mortality rates (or exploitation rates) and, thus, establish sustainable exploitation levels. Yet, this kind of information is usually deficient or inadequate and, when knowledge of stock biology is limited or exploitation data is lacking, such stocks are classified as data-limited stocks (Froese et al., 2012). Uncertainty inherent in data-limited stock assessments could compromise the ability to inform management, which is a concern considering that poorly studied stocks are generally in worse conditions than data-rich stocks (Costello et al., 2012; Hilborn et al., 2020). To overcome this deficiency, increasing research 
75 has been dedicated to developing assessment methods for data-limited fisheries in recent years and has resulted in a suite of assessment tools that can be applied in data-limited situations (Carruthers \& Hordyk, 2018; Chong et al., 2020). Nevertheless, many of these methods still require considerable amounts of data either from fisheries or on the biology of the target species, including time-series data on historical catches, catch-per-unit-effort (CPUE) or scientific survey yield trends and

80 information on the age structure of the stock or life cycle parameters, all of which are difficult to obtain for many data-limited fisheries (Hordyk et al., 2015a).

Within this context, length-frequency data from catches are probably the most common source of demographic information because they are relatively inexpensive and easy to record (Mildenberger et al., 2017). As a result, a number of length-based methods have been developed and applied to estimate biological parameters and understand the dynamics of stocks. This has prompted the development of length-based techniques to estimate fish growth and mortality rates without age data (Hordyk et al., 2015b). Froese (2004) proposed simple fishery indicators based on length composition to provide insights into stock statuses and sustainable exploitation indicators. The mean catch length of a stock has also been used to calculate the status of exploited stocks (Ault et al., 90 2005) to estimate total mortality in fish stocks (Gedamke \& Hoenig, 2006) and to estimate the spawning potential ratio (SPR) in data-limited fisheries (Hordyk et al., 2015b). Among the length-based methods applied to data-limited stocks, the International Council for the Exploration of the Sea (ICES) Workshop on the "Development of Quantitative Assessment 94 Methodologies based on Life-history Traits, Exploitation Characteristics and other Relevant 95 Parameters for Data-limited Stocks" (WKLIFE V) (ICES, 2015) identified the length-based 96 indicator (LBI, methodology developed by ICES, 2015 although some indicators had been 97 introduced previously by Froese, 2004) and length-based spawning potential ratio (LBSPR; Hordyk 
et al., 2015b) methods as the most appropriate to achieve reliable assessments. The LBI method provides a set of length-based indicators selected to analyze catch/landings-length composition and classify the stocks according to conservation, sustainability, yield optimization and maximum sustainable yield (MSY) objectives. On the other hand, the LBSPR method consists of a length-based model to assess stock status by the spawning potential ratio of a fish stock (spawning biomass per recruit (SBPR) in an exploited stock divide to the SBPR value in an unfished stock), measured through length composition data.

Both methods, i.e., LBI and LBSPR, are highly sensitive to biological information assumptions (Rudd et al., 2019). Therefore, it is critical to understand the sensitivity of these approaches to parameter inputs (ICES, 2018; Hordyk et al., 2015b). The truthfulness of the models' results is equally dependent on the total uncertainty of the required life history parameter estimates, the inputs in the methods, and the assumptions made (selectivity, recruitment, etc., see the next sections for more details). Although Chong et al. (2020) indicated that LBSPR was one of the most accurate 111 length-based assessment methods, Hordyk et al. (2015b) showed that the model was extremely 112 sensitive to the variation/misspecification of the $\mathrm{L}_{\infty}$ (i.e., von Bertalanffy asymptotic average maximum body size) and M/k (ratio of natural mortality to von Bertalanffy growth rate) parameters. 114 Most previous studies, such as Hordyk et al. (2015b), mainly focused on the sensitivity analysis of 115 SPR estimates using simulation data rather than real exploited stocks data. Indeed, only a small 116 number of studies have performed parameter sensitivity analyses for these methods with real case 117 studies, among which are Sun et al. (2017) and Hordyk et al. (2015b), who applied it to yellow croaker fish (Larimichthys polyactis) in the Haizhou Bay in China and yellow fin whiting (Sillagos 119 chomburgkii) in the Shark Bay, Australia, respectively.

120 In the North East Atlantic, certain fishery resources, such as anglerfish, blue ling, blackspot 
121 seabream, pollack, and skates, among others, are classified as data-limited stocks (ICES, 2012) and 122 have increasingly drawn the attention of ICES. Within this context our study has two objectives.

123 First, we sought to evaluate the status of 7 different fishery stocks in the Bay of Biscay and Iberian 124 Coast ecoregion (see Table 1 for details of ICES Divisions) using the LBI and LBSPR methods and 125 to compare whether these results concur with currently available knowledge surrounding the state of these stocks. To that end, we checked whether disagreements between both sources of information 127 (i.e., current knowledge vs. our results) may have been related to the noncompliance of model assumptions in each case. Second, we sought to analyze the robustness of these methods as applied to the stocks studied under various scenarios by testing the sensitivity of life history input parameters $\left(\mathrm{M} / \mathrm{k}\right.$, and $\left.\mathrm{L}_{\infty}\right)$. For addressing above aims the following case studies were selected: the southern range of the European anchovy (Engraulis encrasicolus) stock in ICES Division 9a, given that it is one of the most important small pelagic species caught by purse seiners in Spanish waters; Norway lobster (Nephrops norvegicus) Functional Units (FU 26-27 Western Galicia \& Northern Portugal, 9a and in FU 25 North Galicia, 8c), given that they are among the species with the highest economic value caught by bottom trawl fleet in the area; the pouting (Trisopterus luscus), given that it is among the species with high commercial importance caught by Portuguese and Spanish artisanal fleet; the pollack (Pollachius pollachius), which is a bento-pelagic species mainly exploited by France and Spain in a data-limited situation; the lesser spotted dogfish (or small-spotted catshark, 139 Scyliorhinus canicula), given that it is the most frequent and abundant shark species in Iberian 140 Waters; and the blackspot seabream (Pagellus bogaraveo), which, commercially, is one of the most important demersal species in the Strait of Gibraltar area. These stocks all present differences in lifetraits and fishery exploitation levels and were, thus, chosen to ensure that a complete picture of the performance of the methods be tested. 


\section{Material and methods}

\subsection{Stocks data}

The LBI and LBSPR methods were applied to E. encrasicolus, P. bogaraveo, T. luscus, S. canicula, P. pollachius, and N. norvegicus FUs 25 and 26-27 (females) in ICES Divisions 8 and 9a. The selected stocks had not been previously assessed with LBI and LBSPR methods, although other assessments had been previously performed. Specifically, the E. encrasicolus Southern component is scientifically assessed every year by the ICES Working Group on Southern Horse Mackerel, Anchovy and Sardine (WGHANSA) using a GADGET (Globally applicable Area-Disaggregated General Ecosystem Toolbox) model and is considered to be at full reproductive capacity (ICES, 2020a). Since 2014, S. canicula has been assessed every two years by the ICES Working Group on Elasmobranch Fishes (WGEF) using stock indicator trends estimated from survey data and has shown increasing abundance indices since 2014 (ICES, 2020b). As for the $N$. norvegicus FU 25 and 26-27, the advice is triennial and is based on Landing Per Unit Effort (LPUE) trends. Given that biomass is extremely low in these stocks, the advice has been zero catch since 2003 (ICES, 2020c). On the other hand, T. luscus and $P$. pollachius have not been scientifically assessed, although recent studies have indicated signs of potential stock deterioration in specific areas, i.e., Galicia, Spain, based on catch rates and mean size trends (Alonso-Fernández et al., 2019; Alonso-Fernández et al., 2021). Finally, P. bogaraveo is assessed based on a biomass index trend and ICES provides catch advice following a precautionary approach. With the exception of $T$. luscus and $S$. canicula, a total allowable catch (TAC) is applied to these stocks in the study area.

The data required for LBI and LBSPR methods (annual length frequency distributions) for $S$. canicula and $N$. norvegicus FUs were provided from the Spanish bottom trawl fleet by the Spanish 
167 Institute of Oceanography (IEO), and account for the majority of landings of these species. In 168 addition, the IEO provided data for P. bogaraveo from Spanish "Voracera" fleet that had targeted 169 species in the Strait of Gibraltar. Spanish Voracera fleet catch the vast majority of total P. bogaraveo 170 landings in this area. Data for T. luscus were registered by observers onboard the Galician coast 171 multigear artisanal fleet. Although it is difficult to determine the proportion of catches from each 172 type of fishing gear used to target $T$. luscus, for this study we selected the most representative fishing 173 gear (gillnet, called "VETAS") used to catch this fish species (see Alonso-Fernández et al. 2019; 174 2021). P. pollachius data were obtained from the gillnet and longline fleets, neither of which are the 175 dominant fleet. We therefore had to combine the length compositions across fleets by using fleet176 specific catches to weight the proportions before aggregating them together. Data for E. encrasicolus 177 were provided by Spain (IEO) and Portugal (IPMA; Portuguese Institute of the Sea and Atmosphere) 178 from the purse-seine fleet (which is the dominant fleet). These data constitute official information 179 that countries share each year with both ICES and the respective working groups.

180 Note that all the mentioned length compositions represent landed fish. The life history parameters $181\left(\mathrm{M} / \mathrm{k}, \mathrm{L}_{\infty}, \mathrm{L}_{50}\right.$ and $\mathrm{L}_{95}$, length at $50 \%$ and $95 \%$ of maturity, respectively) of each stock are reported in 182 Table 1.

\subsection{The length-based indicators (LBI) method}

184 Length-based indicators are calculated from length frequency distributions obtained from catches or 185 landings and compared to reference levels based on life-history parameters. These indicators are 186 related to conservation, optimal yield, and length distributions relative to MSY expectations and can, 187 thus, provide descriptions of stock status. The LBI method requires the following data: length at maturity (L50 the length at which the probability of having reached maturity is $50 \%$ ), von Bertalanffy asymptotic average maximum body size $\left(\mathrm{L}_{\infty}\right)$, the ratio of natural mortality to von Bertalanffy 
190 growth rate (M/k), and length compositions from catch/landings per year. The length-based indicator $191 \mathrm{~L}_{\max 5 \%}$ (Table 2), which characterizes the upper portion of the length frequency distribution, analyzes 192 the conservation of large individuals by comparing itself to the reference point $\mathrm{L}_{\infty}$. The 193 corresponding ratio provides information on the degree of truncation of the stock length structure 194 that may be caused by fishing, and according to a simulation study performed by Miethe \& Dobby 195 (2015), should be above 0.8. The $\mathrm{P}_{\text {mega }}$ indicator (Table 2) refers to the proportion of mega-spawners in the stock (fish larger than the optimum length $\mathrm{Lopt}_{\mathrm{a}} 3 \mathrm{~L} \infty /(3+(\mathrm{M} / \mathrm{k}))$ plus $\left.10 \%\right)$ and follows the idea 197 summarized by Froese (2004) as "Let the mega-spawners live". Froese (2004) and ICES (2015) have 198 suggested that values above 0.3 correspond to healthy stocks. $\mathrm{P}_{\text {mega }}$ has been included in the analysis 199 only to illustrate with evidences that this indicator should not be used. Length indicators $\mathrm{L}_{25 \%}$ and $\mathrm{L}_{\mathrm{c}}$ 200 relate to the conservation of immature individuals and follow the "Let them spawn" principle 201 (Froese, 2004). The ratio of both indicators to $\mathrm{L}_{50}$ is expected to be greater than 1 (Table 2). Finally, 202 the $\mathrm{L}_{\text {mean }} / \mathrm{L}_{\text {opt }}$ ratio, whose value is expected to be approximately 1, relates to the optimal yield and 203 follows the "Let them grow" principle (Froese, 2004). However, the $\mathrm{L}_{\text {mean }} / \mathrm{L}_{\mathrm{F}=\mathrm{M}}$ ratio, whose value is expected to be equal to or greater than 1 , focuses on MSY considerations given that $\mathrm{L}_{\mathrm{F}=\mathrm{M}}$ is a lengthbased proxy for MSY. To correctly interpret and discuss the results provided by the LBI method, it is crucial to consider that this method assumes that constant mortality and recruitment have created a new steady state, as reflected in the length compositions equilibrium conditions. When this 208 assumption does not hold, results can be misinterpreted. Furthermore, it should be noted that the 209 reference values for each LBI indicator are sensitive to Froese (2004) selectivity assumptions.

\section{2.3. Length-based spawning potential ratio (LBSPR) method}

211 The original LBSPR method described by Hordyk et al. (2015a, b) is based on a conventional age212 structured equilibrium stock model. The method uses maximum likelihood methods to find the 
213 values of relative fishing mortality $(\mathrm{F} / \mathrm{M})$ and selectivity-at-length that minimize the difference 214 between the observed and the expected length compositions of the catch and calculates the resulting 215 SPR. One drawback of the method is that selectivity is age-based rather than length-based, despite 216 the fact that fish selectivity is often length-dependent, and this leads to different fishing mortality 217 rates among fish of the same age; an effect known as "Lee's Phenomenon" (Lee, 1912). Given that 218 the age-structured LBSPR method does not account for Lee's Phenomenon it is assumed to over219 estimate fishing mortality when selectivity is length-dependent. Thus, in this study, we considered an 220 extension of this method, proposed by Hordyk et al. (2016), consisting of a length-structured version 221 of the LBSPR method that uses growth-type-groups (GTG) to account for length-based selectivity 222 (known as the GTG-LBSPR method).

223 The LBSPR method uses length composition data to estimate the spawning potential ratio (SPR) by 224 developing a computationally efficient length-per-recruit-structured model that splits the stock into 225 diverse sub-cohorts, or growth-type-groups, to account for length-dependent fish mortality rates. 226 Furthermore, this method can estimate both F/M and selectivity parameters (assuming logistic 227 selection).

228 The LBSPR method requires the following parameters: the $\mathrm{M} / \mathrm{k}$ ratio, $\mathrm{L}_{\infty}$ and knowledge of 229 maturity-at-size ( $\mathrm{L}_{50}$ and $\mathrm{L}_{95}$, length at 50\% and 95\% maturity, respectively). Furthermore, it applies 230 data on the length composition of the catch to estimate the SPR. Of note is that SPR estimates 231 ranging between 0.35-0.4 are generally associated with a stock at MSY level (Legault and Brooks, 232 2013), whereas SPR estimates ranging below 0.1-0.15 indicate that the stock is close to collapse 233 (such limits have been fixed on the basis of Goodyear, 1993, who pointed out that the risk of collapse 234 increases considerably for SPR values below 0.2). The LBSPR method assumes that length 235 composition data is representative of the exploited stock in a steady state, the selectivity curve is 
236 logistic, and the method is equilibrium based (as with the LBI method). LBSPR also assumes that an 237 overall fishing mortality rate is the cause of the resultant length composition and, thus, assumes that 238 length composition data either come from the dominant fleet or that multiple fleets are combined into 239 one catch-weighted aggregate length composition.

\section{$240 \quad$ 2.4. Sensitivity analysis}

241 To carry out the sensitivity analysis for this study, we first applied the LBI and LBSPR methods 242 using $\mathrm{M} / \mathrm{k}$ and $\mathrm{L}_{\infty}$ values defined after analyzing previous literature and other reliable information on

243 the stock/species (Table 1). In this study we refer to such values as $M / k^{L I T}$ and $L_{\infty}{ }^{L I T}$ and refer to the 244 corresponding setting as the reference setting. Hence, to analyze the underestimation and 245 overestimation effects of these parameters on the model outputs, we reapplied the LBI and LBSPR 246 methods using either a lower or upper bound of one of the two parameters instead of the M/ $\mathrm{k}^{\mathrm{LIT}}$ or $247 \mathrm{~L}_{\infty}{ }^{\mathrm{LIT}}$ reference values. The different settings are summarized in Table 3.

248 The upper and lower bounds of the $\mathrm{M} / \mathrm{k}^{\mathrm{LIT}}$ and $\mathrm{L}_{\infty}^{\mathrm{LIT}}$ parameters in Table 3 were fixed following the 249 ideas put forth in a simulation study carried out by Hordyk et al. (2015b). In addition, M/k=1.5 was 250 considered following Jensen (1996), who suggested that such a value could be close to the optimal 251 value.

252 After applying each method with each of the parameter configurations/settings described in Table 3, 253 the results of the methods in settings 2-6 were compared with the results provided by the methods in 254 the reference setting to analyze the effect of either underestimation or overestimation of the M/k or $255 \mathrm{~L}_{\infty}$ parameters. The metrics used to compare the methods in settings $2-6$ are described below. The 256 first metric was defined for the LBI method. The reference model reports a certain stock status based 
257 on each indicator series. Thus, given the change in the life history parameter (i.e., sensitivity 258 analysis), any change in the stock status time series of an indicator is given as a percentage. More 259 precisely, stock status time series are compared for each year and the number of years that a change 260 is detected is divided by the total number of years in the time series to provide a percentage. Colors 261 are used to distinguish between whether the status has changed to worse or better than the one 262 derived from the reference model. Green percentages indicate that the status has changed to worse 263 than the reference model, whereas red percentages indicate that it has improved. Henceforth, this 264 metric is called the prediction percentage.

265 In addition to analyze the percentage of years that the reference stock status indicator changes, it is 266 also necessary to know how much each indicator has changed in each setting in relation to the 267 reference one. This change is the magnitude of the change regardless of whether the change leads to 268 a change in the stock status or not. Therefore, for both methods, LBI and LBSPR, a second metric, 269 i.e., the annual average of change ratio, is defined as the mean of the annual ratios of the indicator 270 values in the corresponding setting (from 2 to 5; Table 3) over the indicator values in the reference. 271 More precisely, if the time series of any given indicator in the reference setting is $I_{y}^{R}$, with $y$ 272 representing the year, $y=$ year $1, \ldots$, yearL, being year1 the first year for which the length 273 distribution is available and yearL the last year for which such information is provided, and the time 274 series of the same indicator in any of the sensitivity analysis settings is $I_{y}^{S}$, then, the corresponding 275 annual average of change ratio is equal to 
280 An analogous analysis of the one described above for $\mathrm{M} / \mathrm{k}$ and $\mathrm{L}_{\infty}$ settings has been also carried out

\section{on the $\mathrm{L}_{50}$ parameter.}

The methods were implemented using $\mathrm{R}$ software ( $\mathrm{R}$ Core Team, 2019). The LBI method was computed using the utilities.R code available at ICES Tools (development area) Github (https://raw.githubusercontent.com/ices-tools-dev/LBIndicator_shiny/master/utilities.R). This code is a modification of the code used by ICES (2015). The LBSPR method, in turn, was adjusted using the LBSPR R package of Hordyk (2019). The code used in our study can be found at https://github.com/IMPRESSPROJECT/Applying-length-based-methods-to-fisheries-resources-ofthe-Bay-of-Biscay-and-Iberian-Coast.git.

\section{Results}

\subsection{LBI and LBSPR methods to assess stock status}

Stock statuses were assessed from the results of the LBI and LBSPR methods in the reference parameter configurations. The corresponding LBI traffic light indicator tables can be found in the supplementary material, whereas Table 4 reports the outputs for the last year of each stock. Figures 1 and 2 report the results of the LBSPR method (SPR and F/M estimates and their smoother lines from Kalman filter and the Rauch-Tung-Striebel smoother; Rauch et al. 1965). LBSPR estimates are shown as a time series for each parameter configuration to simplify the reporting of results, however it is worth keeping in mind that the LBSPR method treats each year individually and under equilibrium conditions, so there are no links among estimates from different years.

The LBI model outputs suggest that for N. norvegicus FU 25 stock is not exploited at the MSY level, however it does come close in the last years with the optimal yield attained in the last years. 
302 Furthermore, there is a lack of conservation status of large individuals. However, immature 303 individuals would be correctly preserved. The LBSPR results suggest that the N. norvegicus FU 25 304 stocks are below MSY levels, yet above collapse.

305 With respect to the N. norvegicus FU 26-27, although some LBI indicators reflected poor stock 306 status at the beginning of the time series, it was shown to reach a healthy stock status. The LBSPR 307 results also highlighted a healthy stock status (stock at the MSY level).

308 LBI findings highlighted that $S$. canicula stock is exploited close to MSY, optimal yield is obtained 309 and the conservation status of large individuals is adequate. However, there is incorrect preservation 310 of immature individuals for this stock. By contrast, LBSPR results suggested that $S$. canicula stock is 311 not exploited at the MSY level and is close to collapse. Therefore, the conclusions of both 312 assessments do not concur. It should be noted that the indicators for each method are not equivalent, 313 e.g., an SPR greater than $40 \%$ does not mean the same as a $\mathrm{L}_{\text {mean }} / \mathrm{L}_{\mathrm{opt}} \approx 1$ in terms of stock status.

314 LBI results showed that over the last years the E. encrasicolus stock was exploited at close to the 315 MSY level and attained optimal yield. For this stock, immature individuals seem to be well 316 preserved, unlike large individuals given that the proportion of mega-spawners is very low. The 317 LBSPR results suggested that the stock is below the MSY level but above collapse.

318 As for the other stocks, $P$. pollachius was found to be exploited at the MSY level in the last years, 319 the optimal yield came close to being attained in the last year, but the conservation of immature 320 individuals and large individuals were both found to be below the reference points. LBSPR results 321 suggested that stock is below the MSY level but above collapse.

322 Male $P$. bogaraveo are relatively well preserved, unlike the large proportion of mostly female 323 individuals, given that the proportion of mega-spawners is very low. The stock is close to being 324 exploited at the MSY level and optimal yield is close to being attained, but neither levels were 
reached. LBSPR results suggested that the stock is below the MSY level but above collapse.

326 Finally, T. luscus was found to not be exploited at the MSY level. Furthermore, for this species the 327 optimal yield was not attained and the conservation status of large individuals was found to be 328 deficient. However, immature individuals were found to be correctly preserved. The LBSPR method 329 suggested that the stock is not exploited at the MSY level and is close to collapse.

330 In addition to above results, LBSPR estimates of the selectivity parameters (assuming logistic 331 selection) are reported in Figures 3 and 4 of the supplementary material. These figures show that for $332 T$. luscus and P. pollachius, there are limited changes in the selectivity estimates, which is the 333 expected behaviour considering that fishing fleet selectivity has not evolved throughout the years. 334 For $N$. norvegicus and $P$. bogaraveo the selectivity estimates values have increased throughout the 335 years, whereas for $S$. canicula the selectivity estimates values have decreased throughout the years. 336 However, that said, knowledge of the fleet selectivity leads us to assume that it is, in fact, constant. 337 Finally, for E. encrasicolus the estimates of the length at $50 \%$ selectivity are according to the change 338 in the selectivity patterns of the fleet related to a minimum size regulation, however this change is 339 not well represented by the length estimates at $95 \%$ selectivity.

340 Additionally, Table 5 summarizes the LBI and LBSPR results and provides previous knowledge 341 information on stock status, thus enabling a verification of whether or not it matches the LBI and/or 342 the LBSPR assessments. In summary, the LBI assessment is more or less in accordance with 343 previous knowledge on $S$. canicula, $P$. bogaraveo and $T$. luscus, whereas the LBSPR assessment is 344 approximately in accordance with previous knowledge on $P$. bogaraveo. Section 4 discusses the above summary in detail and the possible reasons for divergences between previous knowledge and 346 LBI and LBSPR results.

\subsection{Sensitivity analysis results: LBI and LBSPR}


348 Results from the sensitivity analysis of the LBI approach on the basis of the metric prediction 349 percentage (definition in Subsection 2.4) are summarized in Table 6 for Nephrops, S. canicula, and 350 E. encrasicolus stocks, and in Table 7 for the remaining stocks. Each row reports the information on 351 one of the 7 stocks addressed in the present study.

352 Based on the LBI indicators definition (Table 2), we can assert that, among all the indicators, the 353 underestimation/overestimation of $\mathrm{M} / \mathrm{k}$ can only affect indicators related to the optimal yield, MSY, 354 and conservation of the properties of large individuals. Whereas overestimation and underestimation 355 of $\mathrm{L}_{\infty}$ can affect the $\mathrm{L}_{\text {mean }} / \mathrm{L}_{\text {opt }}, \mathrm{L}_{\text {mean }} / \mathrm{L}_{\mathrm{F}=\mathrm{M}}, \mathrm{P}_{\text {mega }}$ and $\mathrm{L}_{\max } \% / \mathrm{L}_{\infty}$ indicators. Note that indicators of the 356 conservation of immatures are not affected by $\mathrm{L}_{\infty}$ or $\mathrm{M} / \mathrm{k}$ variation.

357 Tables 6 and 7 show that overestimation of $M / k$ and underestimation of $L_{\infty}$ lead to more optimistic 358 perceptions of stock statuses, and vice versa. Although misspecification of both parameters (M/k and $359 \mathrm{~L}_{\infty}$ ) has an impact on the results in the LBI method, the effect is more significant in the case of the $360 \mathrm{~L}_{\infty}$ parameter. Thus, it can be concluded that this parameter is crucial to obtain an accurate assessment. In fact, for all stocks, the higher prediction percentage metric values were found be either overestimate or underestimate $\mathrm{L}_{\infty}$. Moreover, Tables 6 and 7 show that $\mathrm{L}_{\infty}$ variation affects various indicators, i.e., for all stocks the greater number of affected length indicators were found to 364 either underestimate or overestimate $\mathrm{L}_{\infty}$. Note that $T$. luscus was the only stock that did not change 365 from the perception of the stock status when the different M/k were applied in the LBI method. 366 Additional conclusions can be derived if we focus on the values of the annual average of change ratios metric, defined on Subsection 2.4, and reported in Figure 3 for the LBI method. Among the 
368 LBI indicators, $\mathrm{P}_{\text {mega }}$ was found to be the least robust indicator of the variation/misspecification of $369 \mathrm{~L}_{\infty}$ and $\mathrm{M} / \mathrm{k}$, whereas the most robust indicator was found to be $\mathrm{L}_{\text {mean }} / \mathrm{L}_{\mathrm{F}=\mathrm{M}}$. Note that the most robust 370 indicator relates to the MSY property, whereas the least robust indicator corresponds to the 371 conservation of large individuals, more precisely, to the proportion of mega-spawners.

372 Results of the sensitivity analysis performed for the LBSPR method are summarized in Figures 1 and 3732 and show the SPR and F/M estimates and their smoother lines for the alternative 374 configurations/settings (Table 3). These results indicate that either overestimation of $\mathrm{M} / \mathrm{k}$ or 375 underestimation of $\mathrm{L}_{\infty}$ leads to more optimistic perceptions of stock statuses, and vice versa, and that 376 the $\mathrm{L}_{\infty}$ parameter is crucial to achieving accurate assessments given that it has a more significant 377 effect on results. This conclusion is also supported by the annual average of change ratio values, 378 which are also greater under $\mathrm{L}_{\infty}$ variation than under $\mathrm{M} / \mathrm{k}$ variation in both methods (Figures 3 and $3794)$.

380 The annual average of change ratios, Figure 4 for the LBSPR method, suggest that among the 381 LBSPR indicators, the variation/misspecification of $\mathrm{M} / \mathrm{k}$ affects $\mathrm{F} / \mathrm{M}$ and SPR similarly, whereas 382 under $\mathrm{L}_{\infty}$ variation $\mathrm{SPR}$ is more affected than $\mathrm{F} / \mathrm{M}$.

383 By comparing the behaviour of the LBI and LBSPR indicators under M/k misspecification/variation 384 with a focus on the values of the annual average of change ratio, we can derive conclusions on which 385 method, either LBI or LBSPR, is best given uncertainty in $\mathrm{M} / \mathrm{k}$ or $\mathrm{L}_{\infty}$. The indicator most affected by $386 \mathrm{M} / \mathrm{k}$ variation is $\mathrm{P}_{\text {mega }}$, followed by $\mathrm{F} / \mathrm{M}$ and $\mathrm{SPR}$, the latter of which perform similarly. By contrast, 387 the indicator that is most affected by $\mathrm{L}_{\infty}$ variation is also the $\mathrm{P}_{\text {mega }}$ indicator, followed by SPR and 
$\mathrm{F} / \mathrm{M}$, thus, in this case the range of the annual average change ratio is clearly larger for SPR than F/M. Hence, we can conclude that the less robust indicator corresponds to the LBI method ( $\mathrm{P}_{\text {mega }}$ indicator), yet that the remaining LBI method indicators are more robust than the LBSPR indicators when there is uncertainty in the life history input parameters $\left(\mathrm{M} / \mathrm{k}\right.$ and $\left.\mathrm{L}_{\infty}\right)$. However, it is important to consider that LBI indicators are very rough measures of stock statuses, whereas LBSPR measures describe stock statuses more explicitly. Thus, both LBI indicators (with the exception of $\mathrm{P}_{\text {mega }}$ ) and LBSPR measures can be used together to obtain better precision of stock statuses. However, when the results of both methods contradict one another and the values of the life history input parameters are uncertain, although both sets of model assumptions are fulfilled the LBI method indicators (with the exception of $\mathrm{P}_{\text {mega }}$ ) are more reliable than LBSPR indicators, especially when $\mathrm{L}_{\infty}$ is uncertain.

398 Nevertheless, when it comes to stock status, they are less specific. Note that the reference points of LBI indicators depend on Froese (2004) selectivity assumptions whereas LBSPR, as long as logistic selectivity is correct, estimates selectivity and assures the interpretation matches the selectivity.

It is worth mentioning that SPR and $\mathrm{P}_{\text {mega }}$ values are restricted to 0 and1, thus, if values are close to 402 the extremes in the reference setting, slight changes in the values are possible when the method is applied to settings from 2 to 6 (Table 3). For example, if SPR is close to 0 in the reference setting, the values in settings 2 and 5 can only decrease to a minimum of 0 . Thus, the reported change in the indicator will be small due to this lower bound, and not due to its performance. Despite this, it is possible to observe that the values of change in $\mathrm{P}_{\text {mega }}$ and SPR are higher than in other non-bounded indicators, such as $\mathrm{L}_{\text {mean }} / \mathrm{L}_{\text {opt }}$ and $\mathrm{L}_{\text {mean }} / \mathrm{L}_{\mathrm{F}=\mathrm{M}}$. This may be due to the fact that in our study $\mathrm{P}_{\text {mega }}$ is only 0 for T. luscus (in 13 years of the time series) and $N$. norvegicus FU 25 (for 2 years of the time 
410 hand, it should be noted that small absolute changes in low values (values below approximately 0.5 )

411 can seem less relevant even though they lead to high ratio of change values. The absolute difference

412 between both indicator values seem minor, but it is necessary to consider the magnitude of the

413 reference indicator value given that, for example, a change from 0.01 to 0.03 does not have the same 414 importance as a change from 1.01 to 1.03 . This is the reason why larger annual average of change 415 ratio values are observed for $\mathrm{P}_{\text {mega }}$ and SPR when the absolute difference between both values of the 416 indicator appear to not be so distant from each other.

417 In addition, the results of an analogous sensitivity analysis of $\mathrm{L}_{50}$ parameter is reported on the 418 supplementary material (Figures 5 and 6). Underestimation/overestimation of L50 parameter affects $419 \mathrm{~L}_{\mathrm{c}} / \mathrm{L}_{50}$ and $\mathrm{L}_{25} / \mathrm{L}_{50} \mathrm{LBI}$ indicators and SPR estimates (no effect over F/M estimates). The magnitude 420 of the change on $\mathrm{L}_{c} / \mathrm{L}_{50}$ and $\mathrm{L}_{25 \%} / \mathrm{L}_{50}$ is similar to that observed in the $\mathrm{L}_{\infty}$ scenario for indicators $421 \mathrm{~L}_{\text {mean }} / \mathrm{L}_{\mathrm{opt}}$ and $\mathrm{L}_{\max } \% / \mathrm{L}_{\infty}$. The effect of overestimation/underestimation of $\mathrm{L}_{50}$ over the SPR 422 estimates is similar to the overestimation/underestimation effect of M/k and then less crucial that the 423 L variability.

424 Finally, the sensitivity of model outputs was found to vary among species. However, this variation 425 cannot be explained by species life history traits, such as the $\mathrm{L}_{\infty}$ (Figures 1 and 2 in the 426 supplementary material).

\section{Discussion}

429 This is the first practical application of data-limited methods to various relevant commercial stocks 430 in the Bay of Biscay and the Iberian Coast ecoregion waters. Results from the LBI and LBSPR 
methods lead to the stock status perceptions described in Table 5. As previously mentioned, it is 432 important to compare whether these results are aligned with currently available knowledge on the 433 state of these stocks and with the compliance of model assumptions in each case. Table 5 also 434 summarizes this information, which is discussed in detail below.

435 Admittedly, unrealistic results may be related to, for example, non-representative length compositions of the stock or violation of the theoretical assumptions of the model (constant mortality 437 and recruitment or logistic selectivity). Indeed, results from the simulations in Hordyk et al. (2015b) 438 showed that high recruitment variability is likely to cause considerable variation in estimates with the 439 LBSPR method. Hordyk et al. (2015b) also studied the effects violating the logistic selectivity 440 assumption and concluded that the model overestimates F/M and underestimates SPR when applied 441 to data from fisheries with dome-shaped selectivity. On the other hand, the expectation that $\mathrm{P}_{\text {mega }}>0.3$ 442 (LBI method) assumes asymptotic selection. However, if the selection is dome-shaped, the true 443 proportion of mega spawners in the population is unknown.

444 With respect to $N$. norvegicus from FU 25, the LBI and LBSPR results are not consistent with 445 current knowledge on the stock, which is that catches have decreased by $98 \%$ and stock areas have 446 decreased by $63 \%$ throughout the time series and that total allowable catch (TAC) has been zero in 447 the FU since 2017 (ICES, in press; ICES, 2020c). The results of both methods lead to a more 448 optimistic stock status than true stock status, according to previous knowledge. For 2019, the LBI 449 method showed a fishery with low impact on immature individuals and attained optimum yield. This 450 is due to a lack of recruitment that increases the $\mathrm{L}_{c}$ vs. $\mathrm{L}_{50}$ and the $\mathrm{L}_{\text {mean }}$ vs. $\mathrm{L}_{\text {opt. }}$ The LBSPR method 451 shows increasing SPR estimates throughout the time series, which are proportional to decreases in recruitment.

453 With respect to $N$. norvegicus FU 26-27, the healthy stock status derived from the LBI and LBSPR 
454 models were not consistent with current perceptions of the status of this stock, given that ICES have 455 advised zero catch for 2020, 2021 and 2022 based on the extremely low biomass of this stock (ICES, 456 2019). The abundance index from the bottom trawl survey has been decreasing since the 1990s and 457 spatial analyses show a considerable reduction in the $N$. norvegicus distribution area in relation to 458 their historical distribution (Vila et al., 2020).

459 The above disagreements between both sources of information can be attributed to the following 460 reasons. With respect to Nephrops, life history parameters (M/k, L $\left.{ }_{\infty}, \mathrm{L}_{50}, \mathrm{~L} 95\right)$ are highly uncertain.

461 For example, in the case of FU 25, the $\mathrm{L}_{\infty}$ was obtained with the maximum lengths observed in the

462 length composition time series but previous knowledge of $\mathrm{FU}$ and others suggests that $\mathrm{L}_{\infty}$ is clearly 463 underestimated, whereas, for $N$. norvegicus in FU 26-27, biological parameters were estimated in the 4641980 s and they have not yet been updated. An additional limitation to these methods is that they do 465 not take into account the spatial component that is clearly relevant in the case of Nephrops, which 466 inhabits burrows and has a displacement capacity that is limited to 100 meters. Furthermore, fishing 467 intensity has constrained the distribution area, which is now limited to a few spots where the length 468 distribution provides a healthier view. Finally, the model assumptions (constant recruitment and total 469 mortality) are not met for Nephrops.

470 Table 5 shows that for $S$. canicula different results were obtained from the two applied methods. 471 LBSPR results are not consistent with previous knowledge of the stock status, whereas LBI results 472 are consistent with previous knowledge, with the exception of the indicators of conservation of 473 immature individuals, which are below the reference points. This exception may be related to the fact 474 that the otter trawl fleet catches represent almost the whole stock length distribution yet most of the 475 fish are discarded, particularly individuals smaller than $45 \mathrm{~cm}$. Thus juvenile specimens are not well 
represented. Finally, $\mathrm{P}_{\text {mega }}$ estimates may be affected by the fact that growth rates decrease as sexual 477 maturity is attained. This fact, although it can also be presented in other species, is especially 478 important in the elasmobranchs which have more complex reproduction procedures (oviparous, 479 ovoviviparous, viviparous), and even in the oviparous, such as $S$. canicula, as they have to produce 480 ovigerous capsules, which is an extra energy expenditure, see Araya \& Cubillos (2006).

481 With respect to E. encrasicolus, the results of LBI and LBSPR are not consistent with previous 482 knowledge of the stock status (Table 5) and the possible reasons for this are explained below. The 483 low $\mathrm{P}_{\text {mega }}$ value may be related to the differences between catch and stock length distribution. In fact, 484 if we consider the most reliable estimates of stock distribution to be those estimated by the surveys 485 (corresponding to a particular quarter), then they differ from the catch distribution used in our model, 486 mainly because these length-based methods are not effective with a time step shorter than years and, thus, quarterly distributions needed to be transformed into yearly distributions to be included in the model. This transformation greatly increased the variability of catch length distributions. In addition, most of the indicator thresholds were based on life history parameters that need to be updated. The 490 database used to calculate these indicator thresholds was based on data from before 2000 (Millán et 491 al., 1999, Bellido et al., 2000) and, therefore, did not consider the latest fluctuations in stock 493 selectivity patterns of the fleet, including minimum size regulations that were effectively 494 implemented after 2001 (Rincón et al. 2019). The length estimates conducted at 50\% selectivity 495 reproduce this change, however the length estimates at 95\% selectivity do not (Figure 3 in the 496 supplementary material), the latter of which show a maximum around 2001 but then return to similar 497 levels to those at the beginning of the time series. For this to be consistent with the real selectivity, 498 these two periods should have different and marked estimates. 
499 Results for P. bogaraveo derived from the LBI and LBSPR methods are consistent with current 500 stock status perceptions. Note that the reference biological parameters came from the Strait of 501 Gibraltar samplings and should be considered appropriate for this kind of exercise.

502 In the case of $T$. luscus the results derived from LBI are more or less consistent with previous 503 knowledge, whereas result from the LBSPR are not consistent with previous knowledge. Although 504 previous studies have indicated a negative trend in abundance indices for this species in southern 505 Galician small-scale fisheries (Alonso-Fernández et al., 2019), the high F/M ratio estimated by 506 LBSPR does not seem realistic, particularly taking into account the relatively stable pattern found on 507 the northern Galician coast, ICES Division 8c (Alonso-Fernández et al., 2021). In addition, SSF 508 (small-scale fishery) gears commonly used by this fleet, such as gillnets and trammel nets, tend to be 509 characterized by dome-shaped selectivity curves, which do not meet LBI and LBSPR assumptions 510 and actually affect SPR (underestimate) and F/M (overestimate) estimates (Hordyk et al. 2015b). 511 Moreover, dome-shaped selectivity usually has a lower impact on mean size trends than logistic 512 selectivity curves do (e.g., trawling in industrial fisheries) (Erzini et al., 2006), and this hampers the 513 detection of changes in stock statuses throughout the time series.

514 For $P$. pollachius, no assessment method had previously been applied to this stock, so it is not 515 possible to compare the results obtained using length-based methods from an official assessment. 516 Results must be interpreted with caution since the length distribution comes from different fleets 517 with different selectivity curves, even some dome-shaped ones. This fact implies that the mega518 spawners may not be fully caught and $\mathrm{P}_{\text {mega }}$ may be underestimated. Furthermore, dome-shaped 519 selectivity would lead to an underestimate of the SPR, as mentioned above in the discussion on $T$. 520 luscus.

521 The logistic selectivity assumption is usually violated in highly size-selective fisheries (for example 
522 in T. luscus fisheries), and it could be problematic in multifleet fisheries, where stocks are caught in 523 different proportions by multiple gears with different selectivity patterns (for example in $P$. 524 pollachius fisheries). Pons et al. (2019) provide practical advice on how to combine the length 525 composition of a catch from different fleets with different selectivity patterns before applying the 526 LBSPR method. Their recommendation is that when there are multiple fleets with different 527 selectivity patterns targeting a single stock, the length-based models should be applied to the length 528 data from the fleets that target the broadest range of sizes, including juveniles and adults, when these 529 data are available.

530 Knowledge of the selectivity pattern is also required to correctly interpret LBI results. Cope and Punt 531 (2009) concluded that $\mathrm{P}_{\text {mega }}$ showed a wide range of possible values depending on fishery selectivity. 532 Their results challenge the notion that $\mathrm{P}_{\text {mega }}$ values between 0.3 and 0.4 indicate healthy stocks. They 533 illustrated that this assumption can encourage overfishing in certain circumstances (Froese, 2004). 534 Furthermore, our current study has shown that, $\mathrm{P}_{\text {mega }}$ should not be used because it either provides no 535 information or misleading conclusions.

536 Given these conclusions, Cope and Punt (2009) proposed a new measure to distinguish selectivity 537 patterns and construct a decision tree to develop stock status indicators, defined as the sum of the 538 three simple metrics: $\mathrm{P}_{\text {mat }}$ (which reflects exclusive take of mature individuals), $\mathrm{P}_{\mathrm{opt}}$ (which consists 539 primarily of optimal size fish), and $\mathrm{P}_{\text {mega. }}$ Thus, a potential future direction for our analysis to take is 540 to apply Cope and Punt's (2009) approach to analyze the performance of their method for the stocks 541 we analyzed in this study and compare the results with those provided by the classic LBI approach. 542 This study illustrates the sensitivity of the LBI and LBSPR methods to the uncertainty of the life 543 history input parameters. Our sensitivity analysis was performed to examine the effects of the 544 misspecification/variation of two crucial parameters, $M / k$ and $L_{\infty}$, for almost all the Spanish stocks 
545 assessed in the ICES Division covering different taxonomic groups and types of fisheries. Effects of 546 the misspecification/variation of $\mathrm{M} / \mathrm{k}$ and $\mathrm{L}_{\infty}$ must be considered when drawing conclusions on the 547 state of the stocks to prevent further failures in current management. Through our study, we conclude 548 that the influence of life history variation input parameters is very important in both methods. More 549 precisely, we conclude that diverging management decisions can be obtained when the crucial 550 parameter $\mathrm{L}_{\infty}$ is either underestimated or overestimated (see Subsection 3.2 for the details leading to this conclusion). In line with Shephard et al. (2018) we conclude that an unrealistically high $\mathrm{L}_{\infty}$ may

552 lead to false negatives (a poor status result when the true state is good), whereas a low $\mathrm{L}_{\infty}$ may lead 553 to false positives (a good status result when the true status is poor). Best practices to determine fixed 554 values for life history parameters in stock assessments would be to use estimates from stock-specific 555 studies (Rudd et al., 2019). However, when these studies are not available, our practical 556 recommendation is to carry out a sensitivity analysis on these parameters.

557 In our sensitivity analysis, we also compared the reference model results with the results obtained 558 using $\mathrm{M} / \mathrm{k}=1.5$ (suggestion from Jensen, 1996) of the Beverton-Holt life history invariant, BH-LHI. 559 Our results indicate that conclusions derived from the reference model can differ from those derived 560 from an $\mathrm{M} / \mathrm{k}=1.5$ based model. Although it is common to assume that this ratio does not vary, studies 561 have shown that this does not hold. For example, a study in the Kyphosid (Scorpisaequipinnis), in 562 southwestern Australia, showed the M/k value for this species to be 0.33 , which is very far from the 563 BH-LHI of 1.5 (Coulson et al., 2012). On the other hand, Prince et al. (2015) argued that a lack of 564 variation of $\mathrm{M} / \mathrm{k}=1.5$ is more commonly associated with marine mammals. Furthermore, Prince et al. 565 (2015) performed a meta-analysis of 123 marine species (teleosts, chondrichthyes, invertebrates and 
marine mammals) and found that the $\mathrm{M} / \mathrm{k}$ ratio ranged from 0.12 to 3.52 , thus indicating that life

567 history ratios often vary considerably from the BH-LHI. Despite this, it should be noted that M/k is

568 less variable than $\mathrm{L}_{\infty}$, which is not always easy to estimate, especially for data limited species

569 (Charnov, 1993).

570 In our contribution, we applied the LBI and LBSPR methods to assess stocks in the Bay of Biscay 571 and the Iberian Coast ecoregion waters. Application of both methods increased our knowledge of 572 their performance, as we compared the results of both methods with previous knowledge. For some 573 stocks this comparison indicated the need to further study the reasons why these methods do not 574 provide realistic conclusions, i.e., the need to reviewed model assumptions, accuracy of input data, 575 etc. On the other hand, among our previously reported conclusions, our sensitivity analysis revealed 576 that $\mathrm{L}_{\infty}$ is a crucial parameter and that the accuracy of its value is indispensable to obtain reliable 577 results from the methods, thus providing a practical recommendation (see Subsection 3.2 for the 578 details that lead to this conclusion). The sensitivity analysis also shows that $\mathrm{L}_{50}$ parameter is crucial 579 for a reliable conclusion over the immature individuals using LBI method, and equally important as $580 \mathrm{M} / \mathrm{k}$ for SPR estimates (no effect of the L50 variability is found over F/M). Furthermore, aligned with 581 conclusions previously derived in prior studies, we concluded that among the LBI and LBSPR 582 indicators the LBI method $\mathrm{P}_{\text {mega }}$ indicator was the least robust. However, the remaining LBI method 583 indicators were found to be more robust than the LBSPR indicators when uncertainty exists in the 584 life history input parameters $\left(\mathrm{M} / \mathrm{k}, \mathrm{L}_{50}\right.$ and $\left.\mathrm{L}_{\infty}\right)$. Nevertheless, it is important to consider that LBI 585 indicators are very rough measures of stock statuses, whereas LBSPR measures describe stock 586 statuses based on a contrasted indicator, such as the Spawning Potential Ratio (SPR). Thus, both LBI indicators (except $\mathrm{P}_{\text {mega }}$ ) and LBSPR measures can be used together to obtain more precise stock 
status estimates. Yet, if the results from both methods contradict one another and the life history input parameter values are known to be uncertain, and both sets of model assumptions are fulfilled,

590 the LBI method indicators (except for $\mathrm{P}_{\text {mega }}$ ) are more reliable than the LBSPR indicators under 591 uncertain conditions, especially if $\mathrm{L}_{\infty}$ is uncertain. When it comes to stock status, LBI indicators are 592 less specific. Note that LBI indicators have the advantage of being able to be considered 593 individually, i.e. a biased input parameter does not affect all indicators, unlike in LBSPR.

594 On the other hand, when using the LBI method it is important to keep in mind that, as per our study, 595 the most robust indicator corresponds to the MSY property. Among the LBSPR indicators, SPR was 596 found to be more affected than $\mathrm{F} / \mathrm{M}$ by the variation/misspecification of parameter $\mathrm{L}_{\infty}$, whereas under the variation of $\mathrm{M} / \mathrm{k}$ both indicators performed quite similarly.

598 Finally, it is important to note that neither the LBI method, nor the LBSPR method are not recommended for short-living species given that they cannot be applied with a shorter time step than 600 years, for example, quarters (see the case of E. encrasicolus for more details). Furthermore, 601 recruitment in short-living species represents a high proportion of the stock, hence high recruitment 602 variability in short-living species affects the length composition more than in medium or long-term 603 living species. Therefore, equilibrium based methods (LBI and LBSPR) are not recommended for 604 short-living species.

Acknowledgments

607 This study is a contribution to the IMPRESS project (RTI2018-099868-B-I00), ERDF, Ministry of 608 Science, Innovation and Universities - State Research Agency and also of GAIN (Xunta de Galicia), 609 GRC MERVEX (nº IN607-A 2018-4) 
610

611

612

613

614

615

616

617

618

619

620

621

622

623

624

625

626

627

628

629

630

631

632

633

634

635

636

637

638

639

640

641

642

643

644

645

646

647

648

649

650

651

\section{References}

Alemany, J. (2017). Développement d'un cadre Bayésien pour l'évaluation de stocks à données limitées et élaboration de scénarios de gestion, cas particuliers de la seiche (Sepia officinalis) et du lieu jaune (Pollachius pollachius). Ph.D. Thesis. Université Caen Normandie. 262 pp.

Alonso-Fernández, A., Domínguez-Petit, R., Bao, M.; Rivas, C., \& Saborido-Rey, F. (2008). Spawning pattern and reproductive strategy of female pouting Trisopterus luscus (Gadidae) on the Galician shelf of north-western Spain. Aquat Living Resour., 21, 383-393.

https://doi.org/10.1051/alr:2008059

Alonso-Fernández, A., Otero, J., Bañón, R., Campelos, J.M., Quintero, F., Ribó, J., Filgueira, F., Juncal, L., Lamas, F., Gancedo, A., \& Molares, J. (2019). Inferring abundance trends of key species from a highly developed small-scale fishery off NE Atlantic. Fisheries Research, 209, 101-116. https://doi.org/https://doi.org/10.1016/j.fishres.2018.09.011

Alonso-Fernández, A., Otero, J., \& Bañón, R. (2021). Indicators of body size variability in a highly developed small-scale fishery: Ecological and management implications. Ecological Indicators, 121, 107141. https://doi.org/10.1016/j.ecolind.2020.107141

Alonso-Fernández A., Villegas-Rios, D., Valdés-López, M., Olveira-Rodríguez, B., \& Saborido-Rey, F. (2013). Reproductive biology of pollack (Pollachius pollachius) from the Galician shelf (northwest Spain). Journal of the Marine Biological Association of the United Kingdom, 93(7), 19511963. https://doi.org/10.1017/S0025315413000283

Araya, M., \& Cubillos, L.A., (2006). Evidence of two-phase growth in elasmobranchs. Environmental Biology of Fishes 77, 293-300. https://doi.org/10.1007/s10641-006-9110-8

Ault, J.S., Smith, S.G. \& Bohnsack, J.A. (2005). Evaluation of average length as an estimator of exploitation status for the Florida coral-reef fish community. ICES Journal of Marine Science, 62, 417-423. https://doi.org/10.1016/j.icesjms.2004.12.001

Bellido, J. M., Pierce, G. J., Romero, J. L., \& Millán, M. (2000). Use of frequency analysis methods to estimate growth of anchovy (Engraulis encrasicolus L. 1758) in the Gulf of Cádiz (SW Spain). Fisheries Research, 48(2), 107-115. https://doi.org/10.1016/S0165-7836(00)00183-1

Charnov, E. L. (1993). Life History Invariants. Oxford University Press, Oxford. https://doi.org/10.1046/j.1420-9101.1994.7030399.x

Carruthers, T.R., \& Hordyk, A.R. (2018). The Data-Limited Methods Toolkit (DLMtool): An R package for informing management of data-limited populations. Methods in Ecology and Evolution, 9, 2388-2395. https://doi.org/https://doi.org/10.1111/2041-210X.13081 

M. (2020). Performance evaluation of data-limited, length-based stock assessment methods. ICES

CopeMed II. (2019). Report of the CopeMed II Working Group on stock assessment of P. bogaraveo in the Strait of Gibraltar, Malaga, Spain, 28 - 29 October 2019. CopeMed II Technical Documents $\mathrm{N}^{\mathrm{o}} 55$ (GCP/INT/028/SPA-GCP/INT/362/EC). 47

pp. http://www.faocopemed.org/pdf/publications/CopeMedII_TD55.pdf

Cope, J.M. \& Punt, A.E. (2009). Length-Based Reference Points for Data-Limited Situations: Applications and Restrictions. Marine and Coastal Fisheries, 1(1), 169-186. https://doi.org/10.1577/C08-025.1

Costello, C., Ovando, D., Hilborn, R., Gaines, S.D., Deschenes, O., \& Lester, S.E. (2012). Status and solutions for the world's unassessed fisheries. Science, 338, 517-520. https://doi.org/10.1126/science.1223389

Coulson, P. G., Potter, I. C., \& Hall, N. G. (2012). The biological characteristics of Scorpis aequipinnis (Kyphosidae), including relevant comparisons with those of other species and particularly of a heavily exploited congener. Fisheries Research, 125-126, 272-282. http://dx.doi.org/10.1016/j.fishres.2012.02.031

Erzini, K., Gonçalves, J.M.S., Bentes, L., Moutopoulos, D.K., Casal, J.A.H., Soriguer, M.C., Puente, E., Errazkin, L.A., \& Stergiou, K.I. (2006). Size selectivity of trammel nets in southern European small-scale fisheries. Fisheries $\quad$ Research, $\quad 79, \quad 183-201$. https://doi.org/https://doi.org/10.1016/j.fishres.2006.03.004

FAO (2020). The State of World Fisheries and Aquaculture 2020. Sustainability in action. Rome. https://doi.org/10.4060/ca9229en

Fariña, A.C. (1984). Informe de la campaña "Sisargas-83". Inf. Técn. Inst. Esp. Oceanogr., 25, 122.

Fariña, A.C. (1996). Megafauna de la plataforma continental y talud superior de Galicia. Biología de la cigala Nephrops norvegicus. Doctoral thesis. Universidade da Coruña, 1996. 298 pp.

Froese, R. (2004). Keep it simple: three indicators to deal with overfishing. Fish and Fisheries, 5 (1), 86-91. https://doi.org/10.1111/j.1467-2979.2004.00144.x

Froese, R., Zeller, D., Kleisner, K., \& Pauly, D. (2012). What catch data can tell us about the status of global fisheries. Marine biology, 159(6), 1283-1292. https://doi.org/10.1007/s00227-012-1909-6

Gedamke, T. \& Hoenig, J.M. (2006). Estimating mortality from mean length data in nonequilibrium situations, with application to the assessment of Goosefish. Transactions of the American Fisheries Society, 135, 476-487. https://doi.org/10.1577/T05-153.1 
GFCM (in press). Report of the 2020 Working Group on Stock Assessment of Demersal species. General Fisheries Commission for the Mediterranean. Online, 18 -30 January 2021.

Goodyear, C.P. (1993). Spawning stock biomass per recruit in fisheries management: foundation and current use. pp. 67-82. In: Smith, S.J., J.J. Hunt, and D. Rivard [ed.]. Risk evaluation and biological reference points for fisheries management. Can. Spec. Publ. Fish. Aquat. Sci, 120.

Hilborn, R., Amoroso, R.O., Anderson, C.M., Baum, J.K., Branch, T.A., Costello, C., de Moor, C.L., Faraj, A., Hively, D., Jensen, O.P., Kurota, H., Little, L.R., Mace, P., McClanahan, T., Melnychuk, M.C., Minto, C., Osio, G.C., Parma, A.M., Pons, M., Segurado, S., Szuwalski, C.S., Wilson, J.R., \& Ye, Y. (2020). Effective fisheries management instrumental in improving fish stock status. Proceedings of the National Academy of Sciences, 117, 2218-2224. https://doi.org/10.1073/pnas.1909726116

Hordyk, A., Ono, K., Sainsbury, K., Loneragan, N., \& Prince, J. (2015a). Some explorations of the life history ratios to describe length composition, spawning-per-recruit, and the spawning potential ratio. ICES Journal of Marine Science, 72(1), 204-216. https://doi.org/10.1093/icesjms/fst235

Hordyk, A., Ono, K., Valencia, S., Loneragan, N., \& Prince, J. (2015b). A novel length-based empirical estimation method of spawning potential ratio (SPR), and tests of its performance, for small-scale, data-poor fisheries. ICES Journal of Marine Science, 72(1), 217-231. https://doi.org/10.1093/icesjms/fsu004

Hordyk, A. R., Ono, K., Prince, J. D., \& Walters, C. J. (2016). A simple length-structured model based on life history ratios and incorporating size-dependent selectivity: application to spawning potential ratios for data-poor stocks. Canadian Journal of Fisheries and Aquatic Sciences, 73(12), 1787-1799. https://doi.org/10.1139/cjfas-2015-0422

Hordyk, A. (2019). LBSPR: Length-Based Spawning PotentiaL. Ratio. R package version 0.1.4. https://github.com/AdrianHordyk/LBSPR

ICES (2012). Report of the Working Group on assessment of new MoU species (WGNEW). Copenhagen, Denmark. ICES CM 2012/ACOM:20. 258 pp

ICES (2015). Report of the fifth Workshop on the development of quantitative assessment methodologies based on life-history traits, exploitation characteristics and other relevant parameters for data-limited stocks (WKLIFE V). Lisbon, Portugal. Retrieved from http://ices.dk/ sites/pub/Publication Reports/ExpertGroupReport/acom/2015/WKLIFEV/ExSumm_wklifeV 2015.pdf

ICES (2018). Technical Guidelines - ICES reference points for stocks in categories 3 and 4. ICES Technical Guidelines. https://doi.org/10.17895/ices.pub.4128

ICES (2019). Advice basis. In Report of the ICES Advisory Committee, 2019. ICES Advice 2019, Book 1, Section 1.2.https://doi.org/10.17895/ices.pub.4503. 
ICES. (2020a). Working Group on Southern Horse Mackerel, Anchovy and Sardine (WGHANSA). Draft report. ICES Scientific Reports. 2:41. 513 pp.http://doi.org/10.17895/ices.pub.5977 .

ICES (2020b). Report of the working group of elasmobranch fishes (WGEF). ICES Scientific Reports.volume 2 | Issue 77.789 pp. http://doi.org/10.17895/ices.pub.7470

ICES (2020c). Working Group for the Bay of Biscay and the Iberian Waters Ecoregion (WGBIE). ICES Scientific Reports. 2:49. 845 pp. http://doi.org/10.17895/ices.pub.6033.

ICES (2020d). Working Group on the Biology and Assessment of Deep-sea Fisheries Resources (WGDEEP). ICES Scientific Reports. 2:38. 928 pp.http://doi.org/10.17895/ices.pub.6015.

ICES (in press). Benchmark Workshop on the application of SPiCT to produce MSY advice for selected stocks (WKMSYSPiCT). 15-19 February 2021. On line. 285 pp.

Jensen, A.L. (1996). Beverton and Holt life history invariants result from optimal trade-off of reproduction and survival. Can. J. Fish. Aquat. Sci., 53(4), 820-822. http://doi.org/10.1139/f95-233.

Labarta, U., Ferreiro, M.J., Fernández, M.T., \& Martínez, F. (1982a). Spawning season and first maturity size and age of the Galician coast pouting (Trisopterus luscus L.). Council Meeting, 1982, of the International Council for the Exploration of the Sea, (Copenhagen (Denmark)), (11 Oct 1982). COPENHAGEN (DENMARK): ICES

Labarta, U., Ferreiro, M.J., Martínez, F. \& Fernández, M.T., (1982b). Age and growth of the Galician coast pouting (Trisopterus luscus L.). Preliminary data. Council Meeting, 1982, of the International Council for the Exploration of the Sea, (Copenhagen (Denmark)), (11 Oct 1982). COPENHAGEN (DENMARK): ICES

Léauté, J.P., Caill-Milly, N., \& Lissardy, M. (2017). ROMELIGO : Improvement of the fishery knowledge of striped red mullet, whiting and pollack of the Bay of Biscay. The pollack part. Working Document for the Working Group for the Bay of Biscay and Iberian Waters Ecoregion (WGBIE). 4-11 May 2017, Cádiz (Spain). https://archimer.ifremer.fr/doc/00413/52453/

Lee, R. M. (1912). An investigation into the methods of growth determination in fishes by means of scales. ICES Journal of Marine Science, 1(63), 3-34.

Legault, C. \& Brooks, E. N. (2013). Can stock-recruitment points determine which spawning potential ratio is the best proxy for maximum sustainable yield reference points? ICES Journal of Marine Science, 703 (6), 1075-1080. https://doi.org/10.1093/icesjms/fst105

Miethe, T. \& Dobby, H. (2015). Selection of length-based indicators for shellfish stocks and fisheries. Working Document (WD) to WKLIFE V, 5-9 October, Lisbon, 17pp.

Mildenberger, T. K., Taylor, M. H., \& Wolff, M. (2017). TropFishR: an R package for fisheries analysis with length-frequency data. Methods in Ecology and Evolution, 8, 1520-1527. https://doi.org/10.1111/2041-210X.12791 
Millán, M. (1999). Reproductive characteristics and condition status of anchovy Engraulis encrasicolus L. from the Bay of Cadiz (SW Spain). Fisheries Research, 41(1), 73-86. https://doi.org/10.1016/S0165-7836(99)00010-7

Pons, M., Kell, L., Rudd, M.B., Cope, J.M., \& Frédou, F.L. (2019). Performance of length-based data-limited methods in a multifleet context: application to small tunas, mackerels, and bonitos in the Atlantic Ocean, ICES Journal of Marine Science, 76(4), 960-973. https://doi.org/10.1093/icesjms/fsz004

Prince, J., Hordyk, A., Valencia, S.R., Loneragan, N., \& Sainsbury, K. (2015). Revisiting the concept of Beverton-Holt life-history invariants with the aim of informing data-poor fisheries assessment. ICES Journal of Marine Science, 72, 194-203. https://doi.org/10.1093/icesjms/fsu011

Rauch, H.E., Tung, F., \& Striebel, C. T. (1965). Maximum likelihood estimates of linear dynamic systems. AIAA Journal, 3(8), 1445-1450.

R Core Team (2019). R: A language and environment for statistical computing. R Foundation for Statistical Computing, Vienna, Austria. URL .https://www.R-project.org/

Rincón, M. M., Corti, R., Elvarsson, B. T., Ramos, F., \& Ruiz, J. (2019). Granger-causality analysis of integrated-model outputs, a tool to assess external drivers in fishery. Fisheries Research, 213, 4255. http://doi.org/10.1016/j.fishres.2019.01.001

Rodríguez-Cabello, C. (2008). Biologia y ecologia de la pintarroja (Scyliorhinus canicula, L., 1758) en el mar Cantábrico. Tesis doctoral. Universidad de Cantabria. 250 pp.

Rodríguez-Cabello, C., Velasco, F., \& Olaso, I., (1998). Reproductive biology of lesser spotted dogfish Scyliorhinus canicula (L., 1758) in the Cantabrian Sea. Scientia Marina, 62, 3. https://doi.org/10.3989/scimar.1998.62n3187

Rudd, M.B., Thorson, J.T., \& Sagarese, S.R. (2019). Ensemble models for data-poor assessment: accounting for uncertainty in life-history information. ICES Journal of Marine Science, 76, 870-883. https://doi.org/10.1093/icesjms/fsz012

Shephard, S., Davidson, I.C., Walker, A.M., \& Gargan, P.G. (2018). Length-based indicators and reference points for assessing data-poor stocks of diadromous trout Salmo trutta.

Fisheries Research, 199, 36-43. https://doi.org/https://doi.org/10.1016/j.fishres.2017.11.024

Sun, M., Chongliang, Z., Chen, Y., Xu, B., Xue, Y. \& Ren, Y. (2017). Assessing the sensitivity of Data-Limited Methods (DLMs) to the estimation of the life-history parameters from lengthfrequency data. Canadian Journal of Fisheries and Aquatic Sciences. 75. https://doi.org/10.1139/cjfas-2017-0325. 

864
Vila, Y., Salinas, I. \& Gómez, F.J., (2020). Nephrops abundance index estimation from GALNEP19 Survey in FU26 (West Galicia, ICES Division 9a). WD No9. In Working Group for the Bay of Biscay and the Iberian Waters Ecoregion (WGBIE). http://doi.org/10.17895/ices.pub.6033.

\section{Tables}

Table 1: Life history parameter values $\left(\mathrm{M} / \mathrm{k}, \mathrm{L}_{\infty}, \mathrm{L}_{50}\right.$ and $\left.\mathrm{L}_{95}\right)$ for each stock and the corresponding source of information. Stock codes, ICES divisions, and the time series of the length frequency distribution used for each stock are also reported. For $N$. norvegicus FUs 25 and 26-27 stocks, only females were considered. CL: Carapace length.

$* \quad \mathrm{~L}_{95}=1.15 \times \mathrm{L}_{50} * *$ Strait of Gibraltar target fishery data $* * *$ Sexual change (males to females) length

\begin{tabular}{|l|l|l|l|l|l|l|l|}
\hline Stocks & $\begin{array}{l}\text { ICE } \\
\text { S } \\
\text { Div. }\end{array}$ & Stock code & Lo $_{\infty}^{\text {LIT }}$ & M/k ${ }^{\text {LIT }}$ & L50; L95 & Source & $\begin{array}{l}\text { Length } \\
\text { frequency } \\
\text { distribution }\end{array}$ \\
\hline N. norvegicus & $8 c$ & FU25 & $\begin{array}{l}71 \\
\mathrm{~mm} \\
\text { CL }\end{array}$ & 1.9 & $\begin{array}{l}28 ; 32.2^{*} \\
\text { mm CL }\end{array}$ & $\begin{array}{l}\text { Prince et al. } \\
(2015), \\
\text { Fariña } \\
(1984,1996)\end{array}$ & $1982-2019$ \\
\hline
\end{tabular}




\begin{tabular}{|c|c|c|c|c|c|c|c|}
\hline N. norvegicus & $9 a$ & $F U 2627$ & $\begin{array}{l}65 \\
\mathrm{~mm} \\
\mathrm{CL}\end{array}$ & 2.5 & $\begin{array}{l}26 ; 29.9 \\
\mathrm{~mm} \mathrm{CL}\end{array}$ & Fariña (1984) & $1988-2019$ \\
\hline S. canicula & $\begin{array}{l}8 c \\
9 a\end{array}$ & syc. $27.8 c 9 a$ & $\begin{array}{l}75 \\
\mathrm{~cm}\end{array}$ & 1.5 & $\begin{array}{l}54.2 ; 58 \\
\mathrm{~cm}\end{array}$ & $\begin{array}{l}\text { Rodriguez- } \\
\text { Cabello et } \\
\text { al.(1998) } \\
\text { Rodriguez- } \\
\text { Cabello } \\
(2008)\end{array}$ & 2014-2019 \\
\hline E. encrasicolus & $9 a$ & ane.27.9a & $\begin{array}{l}18.95 \\
\mathrm{~cm}\end{array}$ & 1.44 & $\begin{array}{l}11.2 ; 13.3 \\
\mathrm{~cm}\end{array}$ & $\begin{array}{l}\text { Millán } \\
\text { (1999), } \\
\text { Bellido et al. } \\
(2000) \\
\text { ICES } \\
(2020 a)\end{array}$ & 1988-2019 \\
\hline P. bogaraveo & $9 * *$ & sbr.27.9 & $\begin{array}{l}62 \\
\mathrm{~cm}\end{array}$ & 1.42 & $\begin{array}{l}33 ; 35 \\
\mathrm{~cm}^{* * *}\end{array}$ & $\begin{array}{l}\text { CopeMed II } \\
(2019)\end{array}$ & 1997-2019 \\
\hline T. luscus & $\begin{array}{l}8 c \\
9 a\end{array}$ & - & $\begin{array}{l}46.7 \\
\mathrm{~cm}\end{array}$ & 1.76 & $\begin{array}{l}19.2 ; 21.43 \\
\mathrm{~cm}\end{array}$ & $\begin{array}{l}\text { Labarta et al., } \\
\text { (1982a, } \\
\text { 1982b); } \\
\text { Alonso- } \\
\text { Fernández et } \\
\text { al., (2008) }\end{array}$ & 1999-2018 \\
\hline P. pollachius & $\begin{array}{l}8 a b d \\
9 a\end{array}$ & pol.27.89a & $\begin{array}{l}98.2 \\
\mathrm{~cm}\end{array}$ & 1.65 & $\begin{array}{l}42.3 ; 59 \\
\mathrm{~cm}\end{array}$ & $\begin{array}{l}\text { Alemany, } \\
(2017) ; \\
\text { Alonso- } \\
\text { Fernández et } \\
\text { al., (2013); } \\
\text { Léauté et al., } \\
(2017)\end{array}$ & 2010-2018 \\
\hline
\end{tabular}

Table 2: Set of length-based indicators, their references, the corresponding indicator ratios, and their expected values grouped in terms of conservation/sustainability, optimal yield and MSY considerations.

\begin{tabular}{|l|l|l|l|l|l|}
\hline Indicator & Calculation & Reference point & $\begin{array}{l}\text { Indicator } \\
\text { ratio }\end{array}$ & $\begin{array}{l}\text { Expected } \\
\text { value }\end{array}$ & Property \\
\hline $\mathrm{L}_{\text {max } 5 \%}$ & $\begin{array}{l}\text { Mean length of } \\
\text { largest 5\% }\end{array}$ & $\mathrm{L}_{\infty}$ & $\mathrm{L}_{\text {max } 5 \%} / \mathrm{L}_{\infty}$ & $>0.8$ & $\begin{array}{l}\text { Conservation } \\
\text { (large } \\
\text { individuals); } \\
\text { CL }\end{array}$ \\
\hline $\mathrm{P}_{\text {mega }}$ & $\begin{array}{l}\text { Proportion of } \\
\text { individuals } \\
\text { above Lopt }+\end{array}$ & $0.3-0.4$ & $\mathrm{P}_{\text {mega }}$ & $>0.3$ & $\begin{array}{l}\text { Conservation } \\
\text { (large } \\
\text { individuals); }\end{array}$ \\
\hline
\end{tabular}




\begin{tabular}{|c|c|c|c|c|c|}
\hline & $10 \%$ & & & & $\mathrm{CL}$ \\
\hline $\mathrm{L}_{25 \%}$ & $\begin{array}{l}\text { 25th percentile } \\
\text { of length } \\
\text { distribution }\end{array}$ & $\mathrm{L}_{50}$ & $\mathrm{~L}_{25 \%} / \mathrm{L}_{50}$ & $>1$ & $\begin{array}{l}\text { Conservation } \\
\text { (immatures); CI }\end{array}$ \\
\hline $\mathrm{L}_{\mathrm{c}}$ & $\begin{array}{l}\text { Length at first } \\
\text { catch (length at } \\
50 \% \text { of mode) }\end{array}$ & $\mathrm{L}_{50}$ & $\mathrm{~L}_{\mathrm{C}} / \mathrm{L}_{50}$ & $>1$ & $\begin{array}{l}\text { Conservation } \\
\text { (immatures); CI }\end{array}$ \\
\hline $\mathrm{L}_{\text {mean }}$ & $\begin{array}{l}\text { Mean length of } \\
\text { individuals } \\
>L_{c}\end{array}$ & $\begin{array}{l}\mathrm{L}_{\mathrm{opt}}=3 \mathrm{~L}_{\infty} /(3+( \\
\mathrm{M} / \mathrm{k}))\end{array}$ & $\mathrm{L}_{\text {mean }} / \mathrm{L}_{\text {opt }}$ & $\approx 1$ & $\begin{array}{l}\text { Optimal yield; } \\
\text { OY }\end{array}$ \\
\hline $\mathrm{L}_{\text {mean }}$ & $\begin{array}{l}\text { Mean length of } \\
\text { individuals } \\
>L_{c}\end{array}$ & $\begin{array}{l}\mathrm{L}_{\mathrm{F}=\mathrm{M}}=(1-\mathrm{a}) \mathrm{L}_{\mathrm{c}}+\mathrm{a} \mathrm{L}_{\infty} \\
\mathrm{a}=1 /(2(\mathrm{M} / \mathrm{k})+1)\end{array}$ & $\mathrm{L}_{\text {mean }} / \mathrm{L}_{\mathrm{F}=\mathrm{M}}$ & $\geq 1$ & MSY \\
\hline
\end{tabular}

Table 3: Description of the 6 different parameter configurations considered to assess the 886 robustness/sensitivity of LBI and LBSPR methods to estimate the variation/misspecification of 887 parameters $\mathrm{M} / \mathrm{k}$ and $\mathrm{L}_{\infty}$.

\begin{tabular}{|l|l|l|}
\hline Setting & $\mathrm{L}_{\infty}$ value & $\mathrm{M} / \mathrm{k}$ value \\
\hline 1: Reference setting & $\mathrm{L}_{\infty}{ }^{\mathrm{LIT}}$ & $\mathrm{M} / \mathrm{k}^{\mathrm{LIT}}$ \\
\hline 2: Underestimated $\mathrm{M} / \mathrm{k}$ & $\mathrm{L}_{\infty}^{\mathrm{LIT}}$ & $0.75 \cdot \mathrm{M} / \mathrm{k}^{\mathrm{LIT}}$ \\
\hline 3: Overestimated $\mathrm{M} / \mathrm{k}$ & $\mathrm{L}_{\infty}^{\mathrm{LIT}}$ & $1.25 \cdot \mathrm{M} / \mathrm{k}^{\mathrm{LIT}}$ \\
\hline 4: Underestimated $\mathrm{L}_{\infty}$ & $0.75 \cdot \mathrm{L}_{\infty}^{\mathrm{LIT}}$ & $\mathrm{M} / \mathrm{k}^{\mathrm{LIT}}$ \\
\hline 5: Overestimated $\mathrm{L}_{\infty}$ & $1.25 \cdot \mathrm{L}_{\infty}^{\mathrm{LIT}}$ & $\mathrm{M} / \mathrm{k}^{\mathrm{LIT}}$ \\
\hline
\end{tabular}




\begin{tabular}{|l|l|l|}
\hline $6: \mathrm{M} / \mathrm{k}=1.5$ & $\mathrm{~L}_{\infty}^{\text {LIT }}$ & 1.5 \\
\hline
\end{tabular}

889 Table 4: Traffic light indicator table for the last year of each stock. For N. norvegicus FUs 25 and 2689027 stocks, only females were considered.

\begin{tabular}{|c|c|c|c|c|c|c|c|}
\hline & & \multicolumn{4}{|c|}{ Conservation } & \multirow{2}{*}{$\begin{array}{l}\text { Optimizing } \\
\text { Yield } \\
\mathrm{L}_{\text {mean }} / \mathrm{L}_{\mathrm{opt}}\end{array}$} & \multirow{2}{*}{$\begin{array}{l}\text { MSY } \\
\mathrm{L}_{\text {mean }} / \mathrm{LF}_{\mathrm{F}=\mathrm{M}}\end{array}$} \\
\hline Stocks & Year & $\mathrm{L}_{\mathrm{c}} / \mathrm{L}_{50}$ & $\mathrm{~L}_{25 \%} / \mathrm{L}_{50}$ & $\mathrm{~L}_{\max 5 \%} / \mathrm{L}_{\infty}$ & $\mathrm{P}_{\text {mega }}$ & & \\
\hline N. norvegicus FU25 & 2019 & 1.23 & 1.30 & 0.70 & 0.04 & 0.91 & 0.94 \\
\hline $\begin{array}{ll}N . & \text { norvegicus } \\
\text { FU2627 } & \end{array}$ & 2019 & 1.19 & 1.42 & 0.88 & 0.71 & 1.20 & 1.16 \\
\hline S. canicula & 2019 & 0.90 & 0.90 & 0.82 & 0.30 & 1.06 & 0.96 \\
\hline E. encrasicolus & 2019 & 0.98 & 0.98 & 0.79 & 0.05 & 0.95 & 0.93 \\
\hline P. bogaraveo & 2019 & 1.00 & 1.00 & 0.79 & 0.05 & 0.89 & 0.92 \\
\hline T. luscus & 2018 & 1.02 & 1.07 & 0.63 & 0.00 & 0.78 & 0.89 \\
\hline P. pollachius & 2018 & 0.80 & 0.99 & 0.82 & 0.11 & 0.86 & 1.12 \\
\hline
\end{tabular}

Table 5: Summary of the LBI and LBSPR results and previous knowledge information on stock status. Furthermore, the limitations of the application of LBI and LBSPR methods in each stock are briefly explained, with a focus on model assumption compliance. For N. norvegicus FUs 25 and 2627 stocks, only females were considered. CL: conservation of large individuals; OY: optimal yield; MSY: maximum sustainable yield, and CI: conservation of immature individuals. $\boldsymbol{V}$ indicated that the indicator ratios of the corresponding property are above their expected values whereas $\mathbf{X}$ indicates the opposite, $\approx$ indicates that the indicator ratios of the corresponding property are below, but very close to, their expected values. More precisely, MSY, OY and CI indicators close to their expected 
values indicate a value strictly larger than 0.9, 0.8 and 0.9, respectively. MSY $\mathrm{ABOVVE}_{\mathrm{B}}$ and MSY $\mathrm{BELOW}_{\mathrm{W}}$ indicate that the stock is above or below the MSY level, and Collapse ${ }_{\mathrm{ABOVE}}$ and Collapse CLOSE $_{\text {. }}$ indicate that the stock is either above collapse or close to it, respectively.

\begin{tabular}{|c|c|c|c|c|}
\hline Stocks & $\begin{array}{l}\text { LBI stock } \\
\text { status }\end{array}$ & $\begin{array}{l}\text { LBSPR stock } \\
\text { status }\end{array}$ & $\begin{array}{l}\text { Previous knowledge of } \\
\text { stock status }\end{array}$ & $\begin{array}{l}\text { Limitations of LBI } \\
\text { and LBSPR }\end{array}$ \\
\hline $\begin{array}{l}N . \\
\text { norvegicus FU25 }\end{array}$ & $\begin{array}{l}\mathrm{MSY} \approx \\
\mathrm{OY} \boldsymbol{v} \\
\mathrm{Cl} \boldsymbol{\sim} \\
\mathrm{CL} \boldsymbol{x}\end{array}$ & $\begin{array}{l}\text { MSY }_{\text {BELOW }} \\
\text { Collapse }_{\text {ABOVE }}\end{array}$ & $\begin{array}{l}\lfloor\underline{\text { catch trend and }} \\
\text { TAC }=0 \text { (ICES, in press; } \\
\text { ICES, 2020c). }\end{array}$ & \multirow{2}{*}{$\begin{array}{lr}\text { - No constant } & \text { total } \\
\text { mortality } & \text { or } \\
\text { recruitment. } \\
\text { - Life } & \text { history } \\
\text { parameters } & \text { are } \\
\text { uncertain. } & \\
-\quad \text { Need a } & \text { spatial } \\
\text { component. } & \end{array}$} \\
\hline $\begin{array}{l}\text { N. norvegicus } \\
\text { FU2627 }\end{array}$ & $\begin{array}{l}\mathrm{MSY} \boldsymbol{v} \\
\mathrm{OY} \boldsymbol{v} \\
\mathrm{Cl} \\
\mathrm{CL}\end{array}$ & $\begin{array}{l}\text { MSY }_{\mathrm{ABOVE}} \\
\text { Collapse }_{\mathrm{ABOVE}}\end{array}$ & $\begin{array}{l}\text { 主 catch trend and } \\
\text { TAC }=0(\text { ICES, 2019). }\end{array}$ & \\
\hline S. canicula & $\begin{array}{l}\mathrm{MSY} \approx \\
\mathrm{OY} \boldsymbol{\boldsymbol { v }} \\
\mathrm{Cl} \boldsymbol{\times} \\
\mathrm{CL} \boldsymbol{v}\end{array}$ & $\begin{array}{l}\text { MSY } \\
\text { Collapse } \\
\text { Colose }\end{array}$ & $\begin{array}{l}\Lambda_{\text {(ICES, 2020b). }} \\
\text { biomass }\end{array}$ & $\begin{array}{l}\text { Length composition } \\
\text { data does not } \\
\text { represent juvenile } \\
\text { specimens. }\end{array}$ \\
\hline E. encrasicolus & $\begin{array}{l}\mathrm{MSY} \approx \\
\mathrm{OY} \boldsymbol{v} \\
\mathrm{CI} \approx \\
\mathrm{CL} \boldsymbol{x}\end{array}$ & $\begin{array}{l}\text { MSY }_{\text {BELOW }} \\
\text { Collapse }_{\text {ABOVE }}\end{array}$ & $\begin{array}{l}\checkmark \text { Good stock status in } \\
\text { terms of conservation and } \\
\text { exploitation } \\
\text { 2020a). }\end{array}$ & $\begin{array}{l}-\quad \text { Variability of } \\
\text { catch length } \\
\text { distribution. } \\
\text { - Not updated life } \\
\text { history parameters. }\end{array}$ \\
\hline P. bogaraveo & $\begin{array}{l}\mathrm{MSY} \approx \\
\mathrm{OY} \approx \\
\mathrm{Cl} \boldsymbol{\boldsymbol { \sim }} \\
\mathrm{CL} \boldsymbol{X}\end{array}$ & $\begin{array}{l}\text { MSY }_{\text {BELOW }} \\
\text { Collapse }_{\text {ABOVE }}\end{array}$ & $\begin{array}{l}\mathrm{X}_{\text {Overexploitation }} \\
\text { status below MSY levels } \\
\text { (ICES, 2020d and GFCM, } \\
\text { in press). }\end{array}$ & \\
\hline T. luscus & MSY $\mathbf{X}$ & MSY $_{\text {BELOW }}$ & \3 abundance indices & $\begin{array}{ll}\text { No } & \text { logistic } \\
\text { selectivity. }\end{array}$ \\
\hline
\end{tabular}




\begin{tabular}{|c|c|c|c|c|}
\hline & $\begin{array}{ll}\mathrm{OY} & \boldsymbol{x} \\
\mathrm{Cl} & \boldsymbol{v} \\
\mathrm{CL} & \boldsymbol{x}\end{array}$ & Collapse $_{\text {CLOSE }}$ & $\begin{array}{l}\text { trend (Alonso-Fernández } \\
\text { et al., 2019). }\end{array}$ & \\
\hline P. pollachius & $\begin{array}{l}\mathrm{MSY} \\
\mathrm{OY} \approx \\
\mathrm{Cl} \\
\mathrm{CL}\end{array}$ & $\begin{array}{l}\text { MSY }{ }_{\text {BELOW }} \\
\text { Collapse }_{\mathrm{ABOVE}}\end{array}$ & No previous knowledge. & $\begin{array}{ll}\text { No } & \text { logistic } \\
\text { selectivity. } & \end{array}$ \\
\hline
\end{tabular}

912

913

914

915

916

917

918

919

920

921

922

923

924

925

926

927

928

929

930

931

932

933

934

935

936

Table 6: Summary of the results derived from the sensitivity analysis for the whole time series and carried out for the LBI method applied to Nephrops, S. canicula, and E. encrasicolus stocks. For $N$. norvegicus FUs 25 and 26-27 stocks, only females were considered. CL: conservation of large individuals; OY: optimal yield; MSY: maximum sustainable yield. Green:(Red:) lower (higher) estimated indicator value relative to reference scenario. Percentage in brackets indicates the percentage of years that there was a change.

\begin{tabular}{|c|c|c|c|c|c|}
\hline Stock & $0.75 \cdot \mathrm{M} / \mathrm{k}^{\mathrm{LIT}}$ & $1.25 \cdot \mathrm{M} / \mathrm{k}^{\mathrm{LIT}}$ & $0.75 \cdot \mathrm{L}_{\infty}^{\mathrm{LIT}}$ & $1.25 \cdot \mathrm{L}_{\infty}^{\mathrm{LIT}}$ & $\mathrm{M} / \mathrm{k}=1.5$ \\
\hline N. norvegicus FU25 & $\begin{array}{l}\text { OY: } \\
\mathrm{L}_{\text {mean }} / \mathrm{L}_{\mathrm{opt}} \\
(32 \%) \\
\text { MSY: } \\
\mathrm{L}_{\text {mean }} / \mathrm{L}_{\mathrm{F}=\mathrm{M}}(8 \%)\end{array}$ & $\begin{array}{l}\text { CL: } \\
\mathrm{P}_{\text {mega }}(3 \%) \\
\text { OY: } \\
\mathrm{L}_{\text {mean }} / \mathrm{L}_{\text {opt }} \\
(47 \%) \\
\text { MSY: } \\
\mathrm{L}_{\text {mean }} / \mathrm{L}_{\mathrm{F}=\mathrm{M}} \\
(21 \%)\end{array}$ & $\begin{array}{l}\text { CL: } \\
\mathrm{L}_{\text {max } 5 \% / L_{\infty}} \\
(100 \%) \\
\mathrm{P}_{\text {mega }}(89 \%) \\
\text { OY: } \\
\mathrm{L}_{\text {mean }} / \mathrm{L}_{\text {opt }} \\
(68 \%) \\
\text { MSY: }\end{array}$ & $\begin{array}{l}\text { OY: } \\
\mathrm{L}_{\text {mean }} / \mathrm{L}_{\text {opt }} \\
(32 \%) \\
\text { MSY: } \\
\mathrm{L}_{\text {mean }} / \mathrm{L}_{\mathrm{F}=\mathrm{M}}(8 \%)\end{array}$ & $\begin{array}{l}\text { OY: } \\
\mathrm{L}_{\text {mean }} / \mathrm{L}_{\mathrm{opt}} \\
(32 \%) \\
\text { MSY: } \\
\mathrm{L}_{\text {mean }} / \mathrm{L}_{\mathrm{F}=\mathrm{M}} \\
(8 \%)\end{array}$ \\
\hline
\end{tabular}




\begin{tabular}{|c|c|c|c|c|c|}
\hline & & & $\begin{array}{l}\mathrm{L}_{\text {mean }} / \mathrm{L}_{\mathrm{F}=\mathrm{M}} \\
(84 \%)\end{array}$ & & \\
\hline N. norvegicus FU2627 & $\begin{array}{l}\text { CL: } \\
\mathrm{P}_{\text {mega }}(38 \%) \\
\text { OY: } \\
\mathrm{L}_{\text {mean }} / \mathrm{L}_{\text {opt }} \\
(19 \%) \\
\text { MSY: } \\
\mathrm{L}_{\text {mean }} / \mathrm{L}_{\mathrm{F}=\mathrm{M}} \\
(31 \%)\end{array}$ & $\begin{array}{l}\text { CL: } \\
\mathrm{P}_{\text {mega }}(9 \%) \\
\text { OY: } \\
\mathrm{L}_{\text {mean }} / \mathrm{L}_{\text {opt }}(9 \%) \\
\text { MSY: } \\
\mathrm{L}_{\text {mean }} / \mathrm{L}_{\mathrm{F}=\mathrm{M}}(9 \%)\end{array}$ & $\begin{array}{l}\text { CL: } \\
\mathrm{L}_{\text {max } 5 \% L_{\infty}} \\
(47 \%) \\
\mathrm{P}_{\text {mega }}(38 \%) \\
\text { OY: } \\
\mathrm{L}_{\text {mean }} / \mathrm{L}_{\text {opt }} \\
(16 \%) \\
\text { MSY: } \\
\mathrm{L}_{\text {mean }} / \mathrm{L}_{\mathrm{F}=\mathrm{M}} \\
(12 \%)\end{array}$ & $\begin{array}{l}\text { CL: } \\
\mathrm{L}_{\text {max } 5 \% / L_{\infty}} \\
(47 \%) \\
P_{\text {mega }}(53 \%) \\
\text { OY: } \\
\mathrm{L}_{\text {mean }} / \mathrm{L}_{\text {opt }} \\
(53 \%) \\
\text { MSY: } \\
\mathrm{L}_{\text {mean }} / \mathrm{L}_{\mathrm{F}=\mathrm{M}} \\
(50 \%)\end{array}$ & $\begin{array}{l}\text { CL: } \\
\mathrm{P}_{\text {mega }}(53 \%) \\
\text { OY: } \\
\mathrm{L}_{\text {mean }} / \mathrm{L}_{\text {opt }} \\
(44 \%) \\
\text { MSY: } \\
\mathrm{L}_{\text {mean }} / \mathrm{L}_{\mathrm{F}=\mathrm{M}} \\
(50 \%)\end{array}$ \\
\hline S. canicula & $\begin{array}{l}\text { CL: } \\
\mathrm{P}_{\text {mega }}(50 \%)\end{array}$ & $\begin{array}{l}\text { CL: } \\
\mathrm{P}_{\text {mega }}(50 \%)\end{array}$ & $\begin{array}{l}\text { CL: } \\
\mathrm{P}_{\text {mega }}(50 \%) \\
\text { MSY: } \\
\mathrm{L}_{\text {mean }} / \mathrm{L}_{\mathrm{F}=\mathrm{M}} \\
(100 \%)\end{array}$ & $\begin{array}{l}\text { CL: } \\
\mathrm{P}_{\text {mega }}(50 \%) \\
\mathrm{L}_{\text {max } 5 \%} \mathrm{~L}_{\infty} \\
(100 \%) \\
\text { OY: } \\
\mathrm{L}_{\text {mean }} / \mathrm{L}_{\mathrm{opt}} \\
(100 \%)\end{array}$ & \\
\hline E. encrasicolus & $\begin{array}{l}\text { OY: } \\
\mathrm{L}_{\text {mean }} / \mathrm{L}_{\text {opt }} \\
(56 \%) \\
\text { MSY: } \\
\mathrm{L}_{\text {mean }} / \mathrm{L}_{\mathrm{F}=\mathrm{M}}(6 \%)\end{array}$ & $\begin{array}{l}\text { OY: } \\
\mathrm{L}_{\text {mean }} / \mathrm{L}_{\text {opt }} \\
(22 \%) \\
\text { MSY: } \\
\mathrm{L}_{\text {mean }} / \mathrm{L}_{\mathrm{F}=\mathrm{M}} \\
(19 \%)\end{array}$ & $\begin{array}{l}\text { CL: } \\
\mathrm{L}_{\text {max } 5 \%} / \mathrm{L}_{\infty} \\
(81 \%) \\
\mathrm{P}_{\text {mega }}(97 \%) \\
\text { OY: } \\
\mathrm{L}_{\text {mean }} / \mathrm{L}_{\text {opt }} \\
(31 \%) \\
\text { MSY: } \\
\mathrm{L}_{\text {mean }} / \mathrm{L}_{\mathrm{F}=\mathrm{M}} \\
(75 \%)\end{array}$ & $\begin{array}{l}\text { CL: } \\
\mathrm{L}_{\text {max }} \sigma_{\%} \mathrm{~L}_{\infty} \\
(19 \%) \\
\text { OY: } \\
\mathrm{L}_{\text {mean }} / \mathrm{L}_{\text {opt }} \\
(66 \%) \\
\text { MSY: } \\
\mathrm{L}_{\text {mean }} / \mathrm{L}_{\mathrm{F}=\mathrm{M}}(6 \%)\end{array}$ & $\begin{array}{l}\text { MSY: } \\
\mathrm{L}_{\text {mean }} / \mathrm{L}_{\mathrm{F}=\mathrm{M}} \\
(3 \%)\end{array}$ \\
\hline
\end{tabular}

Table 7: Summary of the results derived from the sensitivity analysis for the whole time series and carried out for the LBI method applied to $P$. bogaraveo, $T$. luscus, and P. pollachius. CL: conservation of large individuals; OY: optimal yield; MSY: maximum sustainable yield. 940 Green:(Red:) lower (higher) estimated indicator value relative to reference scenario. Percentage in 941 brackets indicates the percentage of years that there was a change.

\begin{tabular}{|c|c|c|c|c|c|}
\hline Stock & $0.75 \cdot \mathrm{M} / \mathrm{k}^{\mathrm{LIT}}$ & $1.25 \cdot \mathrm{M} / \mathrm{k}^{\mathrm{LIT}}$ & $0.75 \cdot \mathrm{L}_{\infty}{ }^{\mathrm{LIT}}$ & $1.25 \cdot \mathrm{L}_{\infty}{ }^{\mathrm{LIT}}$ & $\mathrm{M} / \mathrm{k}=1.5$ \\
\hline P. bogaraveo & $\begin{array}{l}\text { OY: } \\
\mathrm{L}_{\text {mean }} / \mathrm{L}_{\text {opt }}(17 \%) \\
\text { MSY: } \\
\mathrm{L}_{\text {mean }} / \mathrm{L}_{\mathrm{F}=\mathrm{M}}(4 \%)\end{array}$ & $\begin{array}{l}\text { OY: } \\
\mathrm{L}_{\text {mean }} / \mathrm{L}_{\text {opt }}(78 \%) \\
\text { MSY: } \\
\mathrm{L}_{\text {mean }} / \mathrm{L}_{\mathrm{F}=\mathrm{M}}(22 \%)\end{array}$ & $\begin{array}{l}\text { CL: } \\
\mathrm{L}_{\text {max } 5 \%} / \mathrm{L}_{\infty}(22 \%) \\
\mathrm{P}_{\text {mega }}(100 \%) \\
\text { OY: } \\
\mathrm{L}_{\text {mean }} / \mathrm{L}_{\text {opt }}(83 \%) \\
\text { MSY: } \\
\mathrm{L}_{\text {mean }} / \mathrm{L}_{\mathrm{F}=\mathrm{M}}(91 \%)\end{array}$ & $\begin{array}{l}\text { CL: } \\
L_{\text {maxs }} L_{\infty}(74 \%) \\
\text { OY: } \\
L_{\text {mean }} / L_{\text {opt }}(17 \%) \\
\text { MSY: } \\
L_{\text {mean }} / L_{\mathrm{F}=\mathrm{M}}(4 \%)\end{array}$ & $\begin{array}{l}\text { OY: } \\
\mathrm{L}_{\text {mean }} / \mathrm{L}_{\text {opt }}(35 \%) \\
\text { MSY: } \\
\mathrm{L}_{\text {mean }} / \mathrm{L}_{\mathrm{F}=\mathrm{M}}(4 \%)\end{array}$ \\
\hline T. luscus & & & $\begin{array}{l}\text { CL: } \\
\mathrm{L}_{\max 5 \%} / \mathrm{L}_{\infty}(80 \%)\end{array}$ & & \\
\hline
\end{tabular}




\begin{tabular}{|c|c|c|c|c|c|}
\hline & & & $\begin{array}{l}\mathrm{P}_{\text {mega }}(5 \%) \\
\text { OY: } \\
\mathrm{L}_{\text {mean }} / \mathrm{L}_{\text {opt }}(100 \%) \\
\text { MSY: } \\
\mathrm{L}_{\text {mean }} / \mathrm{L}_{\mathrm{F}=\mathrm{M}}(40 \%)\end{array}$ & & \\
\hline P. pollachius & $\begin{array}{l}\text { OY: } \\
\text { Lmean/Lopt }(22 \%) \\
\text { MSY: } \\
\text { Lmean/LF=M } \\
(11 \%)\end{array}$ & $\begin{array}{l}\text { OY: } \\
L_{\text {mean }} / L_{\text {opt }}(33 \%) \\
\text { MSY: } \\
L_{\text {mean }} / L_{F=M}(33 \%)\end{array}$ & $\begin{array}{l}\text { CL: } \\
\mathrm{L}_{\text {maxs\%/ }} \mathrm{L}_{\infty}(89 \%) \\
\mathrm{P}_{\text {mega }}(56 \%) \\
\text { MSY: } \\
\mathrm{L}_{\text {mear }} / \mathrm{L}_{\mathrm{F}=\mathrm{M}}(56 \%) \\
\text { OY: } \\
\mathrm{L}_{\text {mean }} / \mathrm{L}_{\text {opt }}(67 \%)\end{array}$ & $\begin{array}{l}\text { OY: } \\
L_{\text {mean }} / L_{\text {opt }}(22 \%) \\
\text { MSY: } \\
L_{\text {mean }} / L_{\mathrm{F}=\mathrm{M}}(22 \%) \\
\text { CL: } \\
\mathrm{L}_{\text {max } 5 \% /} L_{\infty}(11 \%)\end{array}$ & $\begin{array}{l}\text { OY: } \\
\mathrm{L}_{\text {mean }} / \mathrm{L}_{\text {opt }}(11 \%)\end{array}$ \\
\hline
\end{tabular}

\section{Figures}

Figure 1: SPR and F/M estimate plots and their smoother lines derived from the sensitivity analysis performed for the LBSPR method applied to N. norvegicus FU25 and FU2627, S. canicula and E. encrasicolus. In the SPR plot, horizontal dotted lines delimit the range in which the stock is considered at the MSY level, whereas horizontal dashed lines represent the levels below which the stock is considered to be collapsed. In the F/M plot, the horizontal dotted line corresponds to the reference value of 1 . For $S$. canicula, the dark blue line and points $(\mathrm{M} / \mathrm{k}=1.5 \mathrm{setting})$ is missing as it overlaps with the black line and points (reference) given that $\mathrm{M} / \mathrm{k}^{\mathrm{LIT}}$ is 1.5 . An unexpected high $\mathrm{F} / \mathrm{M}$ estimate $(\approx 150)$ for $E$. encrasicolus was observed yet was not plotted since the remaining lines and dots are compacted. Note that for $N$. norvegicus the plots refer to carapace length in $\mathrm{mm}$. 


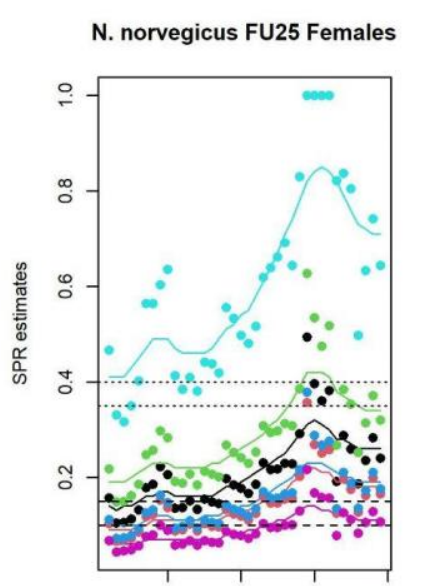

$\begin{array}{llll}1990 \quad 2000 & 2010 \quad 2020\end{array}$ Years

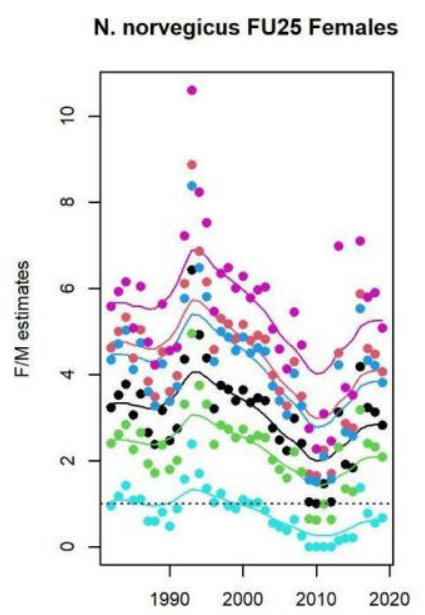

Years

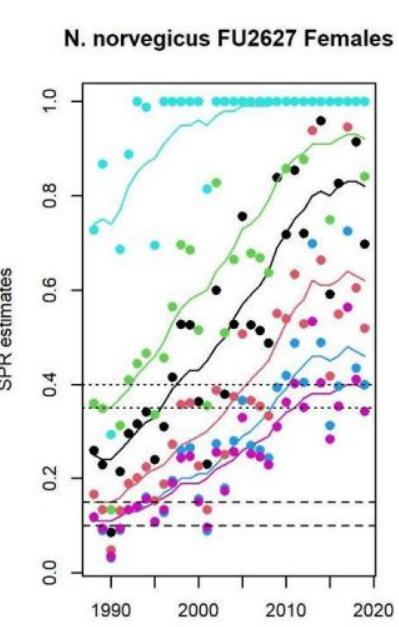

Years

N. norvegicus FU2627 Females

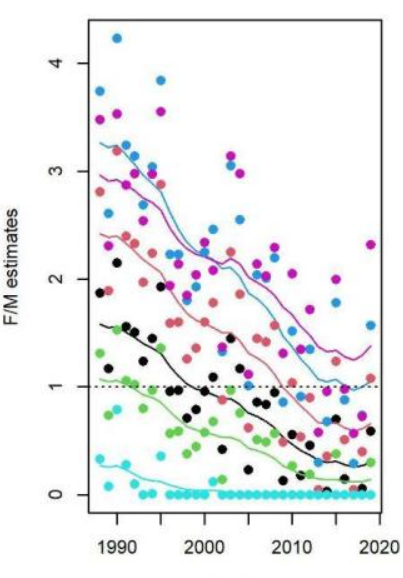

Years
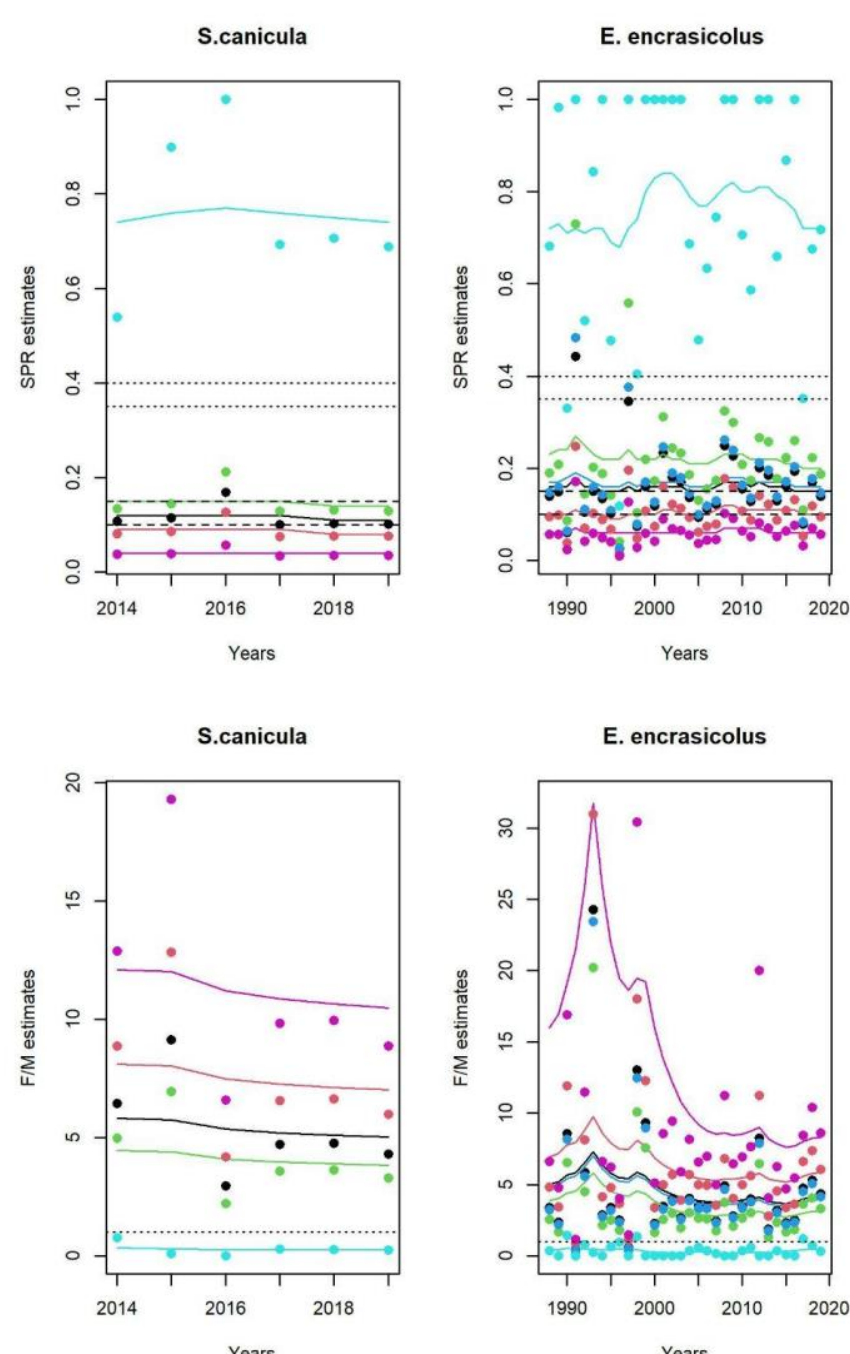

Years

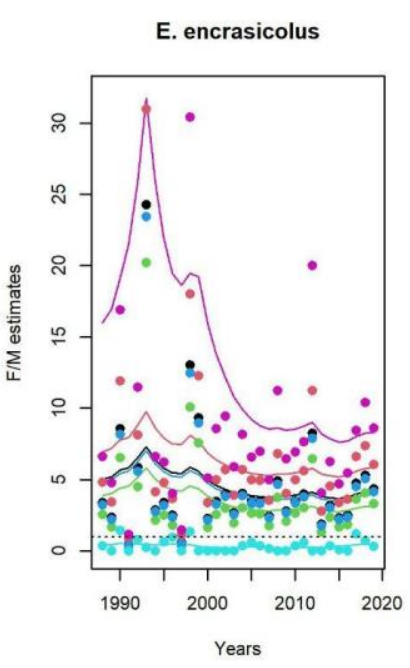

- REFERENCE $-0.75^{*} \mathrm{M} / \mathrm{k} \quad-1.25^{\star} \mathrm{M} / \mathrm{k}$

- $M / k=1.5$

$-0.75^{*} \mathrm{~L} \_$inf

$-1.25^{*} \mathrm{~L} \_$inf 
Figure 2: Plots of the SPR and F/M estimates and their smoother lines derived from the sensitivity analysis carried out for the LBSPR method applied to P. bogaraveo, $T$. luscus, and $P$. pollachius. In the SPR plot, horizontal dotted lines delimit the range where the stock is considered at the MSY level, whereas horizontal dashed lines show the levels below which the stock is considered to be collapsed. In the F/M plot, the horizontal dotted line corresponds to the reference value of 1 . 

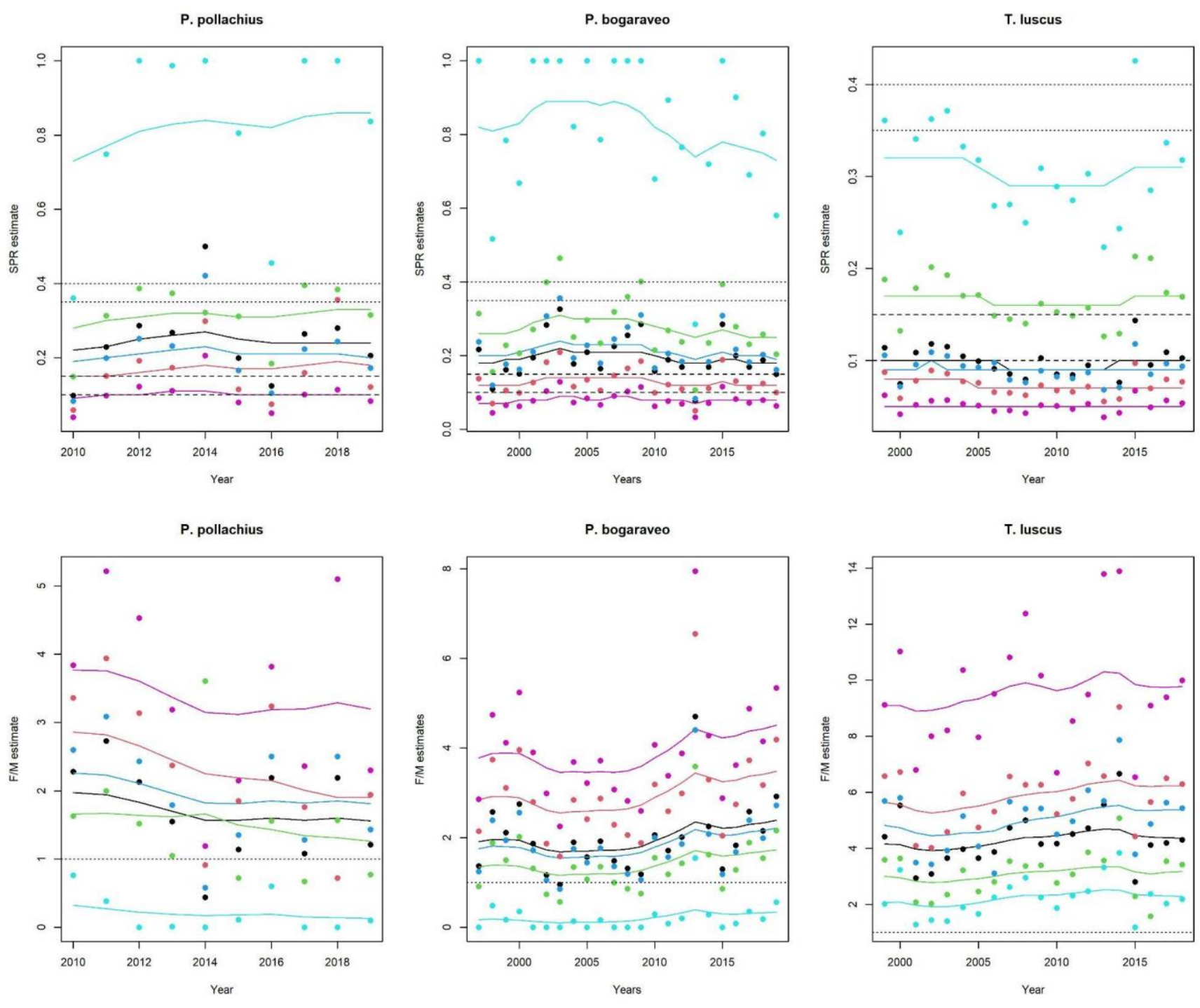

- REFERENCE - $0.75^{*} \mathrm{M} / \mathrm{k}$

$-1.25^{*} \mathrm{M} / \mathrm{k}$

- M/k=1.5

$-0.75^{*} L$ inf

$-1.25^{*} \mathrm{~L}$-inf 
Figure 3: For each stock LBI indicator and setting, the annual average of change ratios (termed output change), defined as the mean of the annual ratios of the indicator values for the corresponding setting (from 2 to 5; Table 3) over the values of the indicator in the reference setting, are plotted as a dot for each stock. Furthermore, the associated standard deviation is represented by a vertical line whose extremes are the mean plus or minus the standard deviation. The left panel shows the results of the sensitivity analysis of the $\mathrm{M} / \mathrm{k}$ parameter (overestimation in green and underestimation in red), whereas the right panel shows the results of the sensitivity analysis of the $\mathrm{L}_{\infty}$ parameter (overestimation in magenta and underestimation in blue). Note that no change of indicator $\mathrm{L}_{\max 5 \% / \mathrm{L}_{\infty}}$ is derived from variation of $\mathrm{M} / \mathrm{k}$ and, hence, the green and red dots overlap and are equal to 1 . 


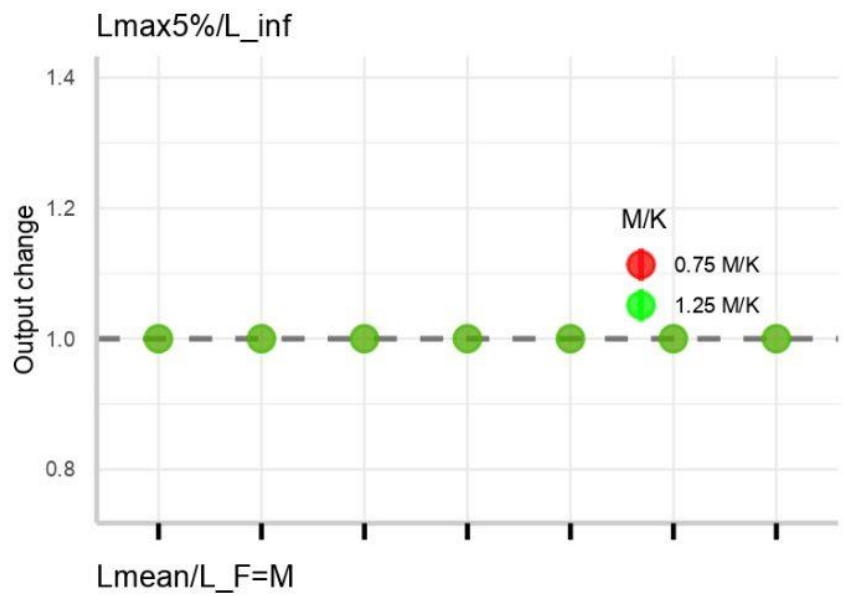

Lmax5\%/L_inf
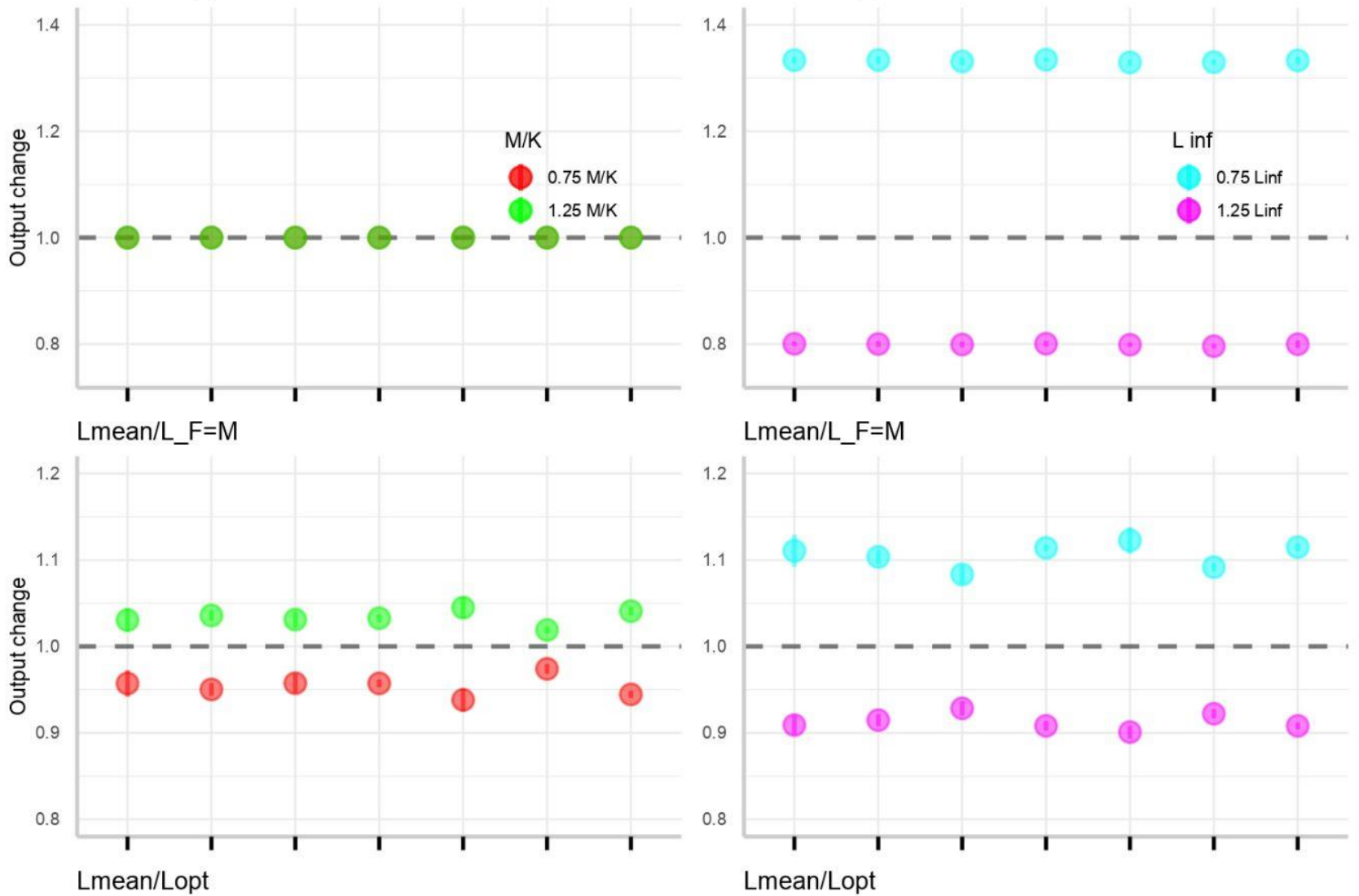

Lmean/L_F=M
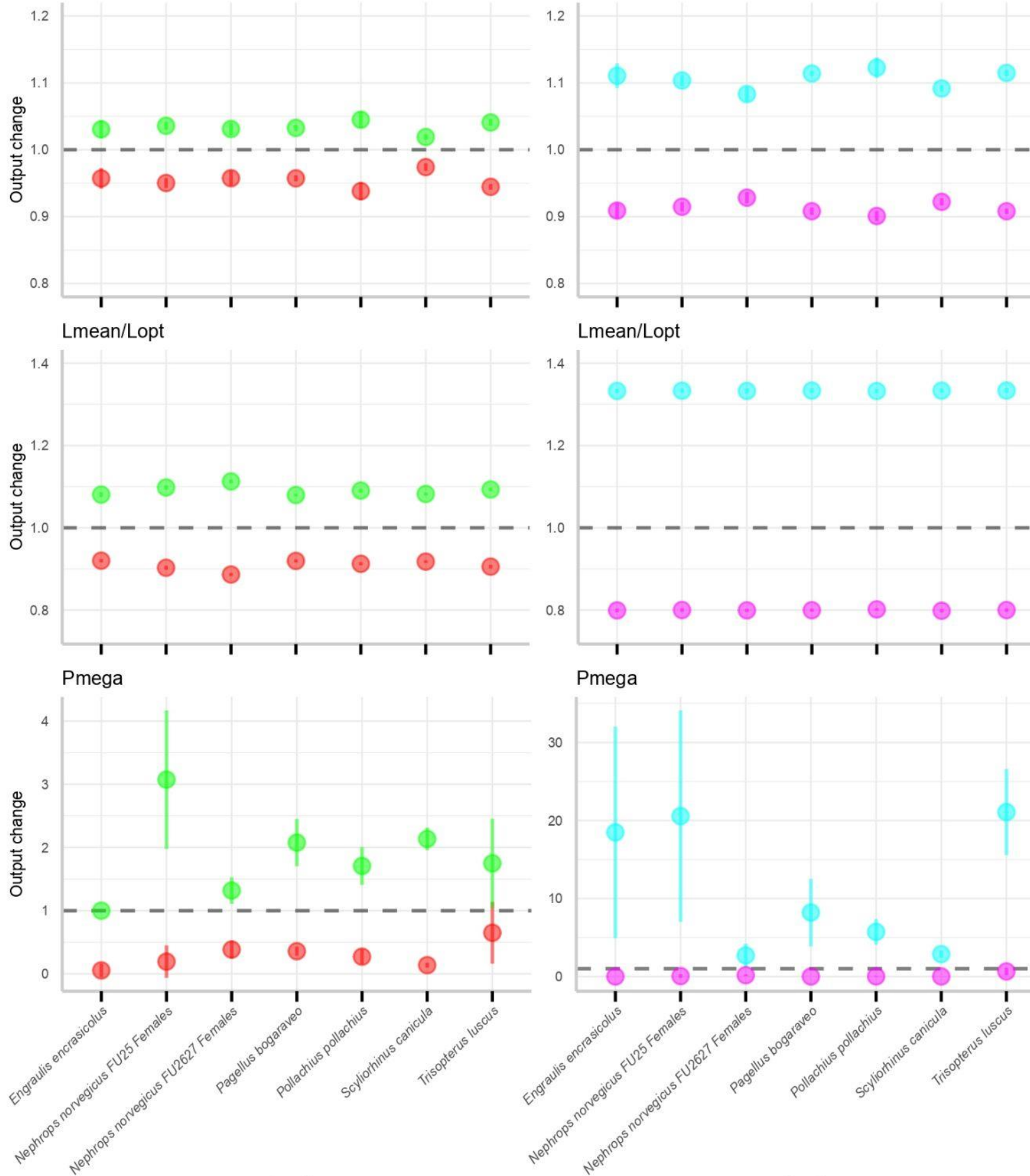
Figure 4: For each stock, LBSPR indicator, and setting, the annual average of change ratios (termed output change), which is defined as the mean of the annual ratios of the indicator values in the corresponding setting (from 2 to 5; Table 3) over the values of the indicator in the reference setting, are plotted as a dot for each stock. Furthermore, the associated standard deviation is represented by a vertical line whose extremes are the mean plus or minus the standard deviation. The left panel shows the results of the sensitivity analysis of the $\mathrm{M} / \mathrm{k}$ parameter (overestimation in green and underestimation in red), whereas the right panel shows the results of the sensitivity analysis of the $\mathrm{L}_{\infty}$ parameter (overestimation in magenta and underestimation in blue). 


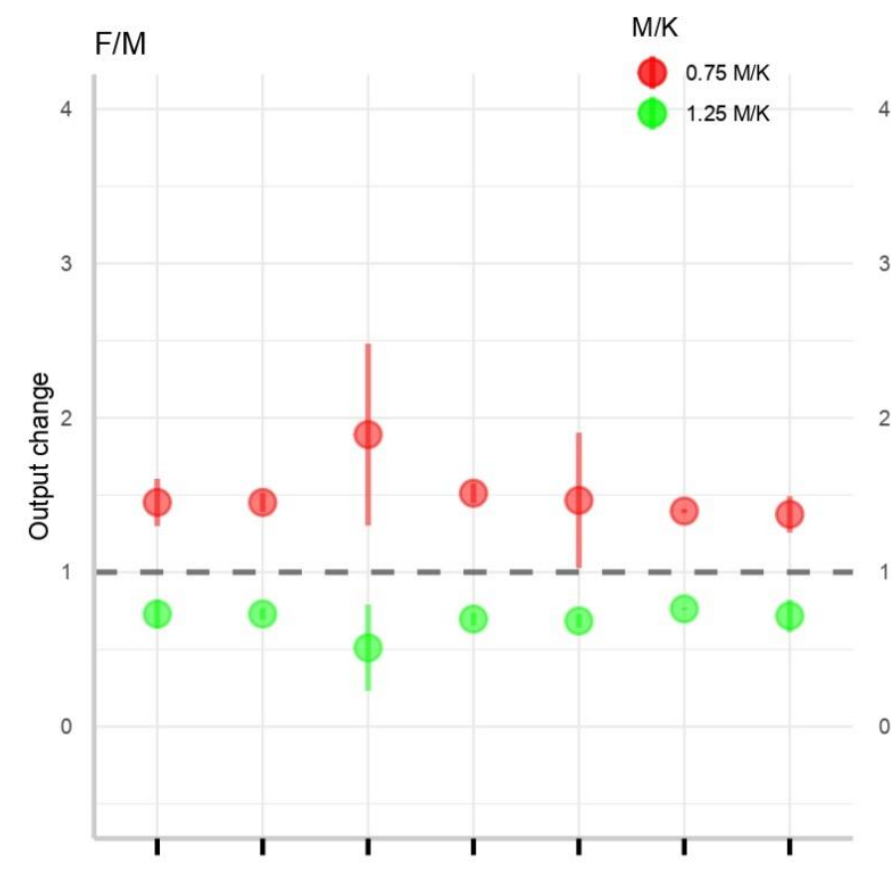

F/M

L inf

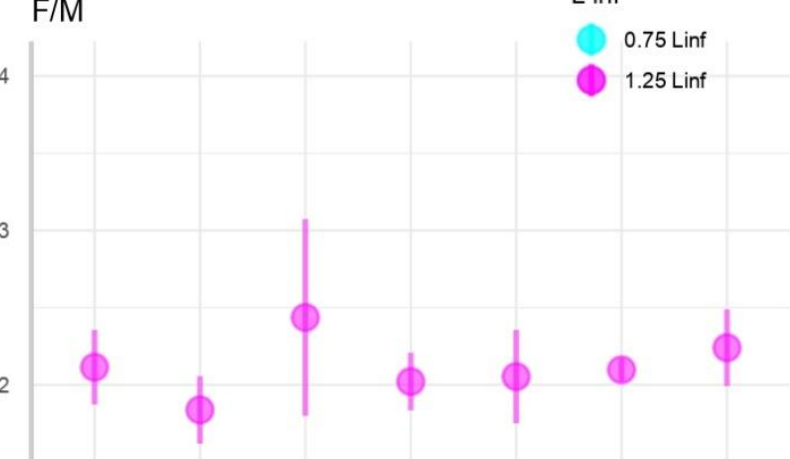

SPR
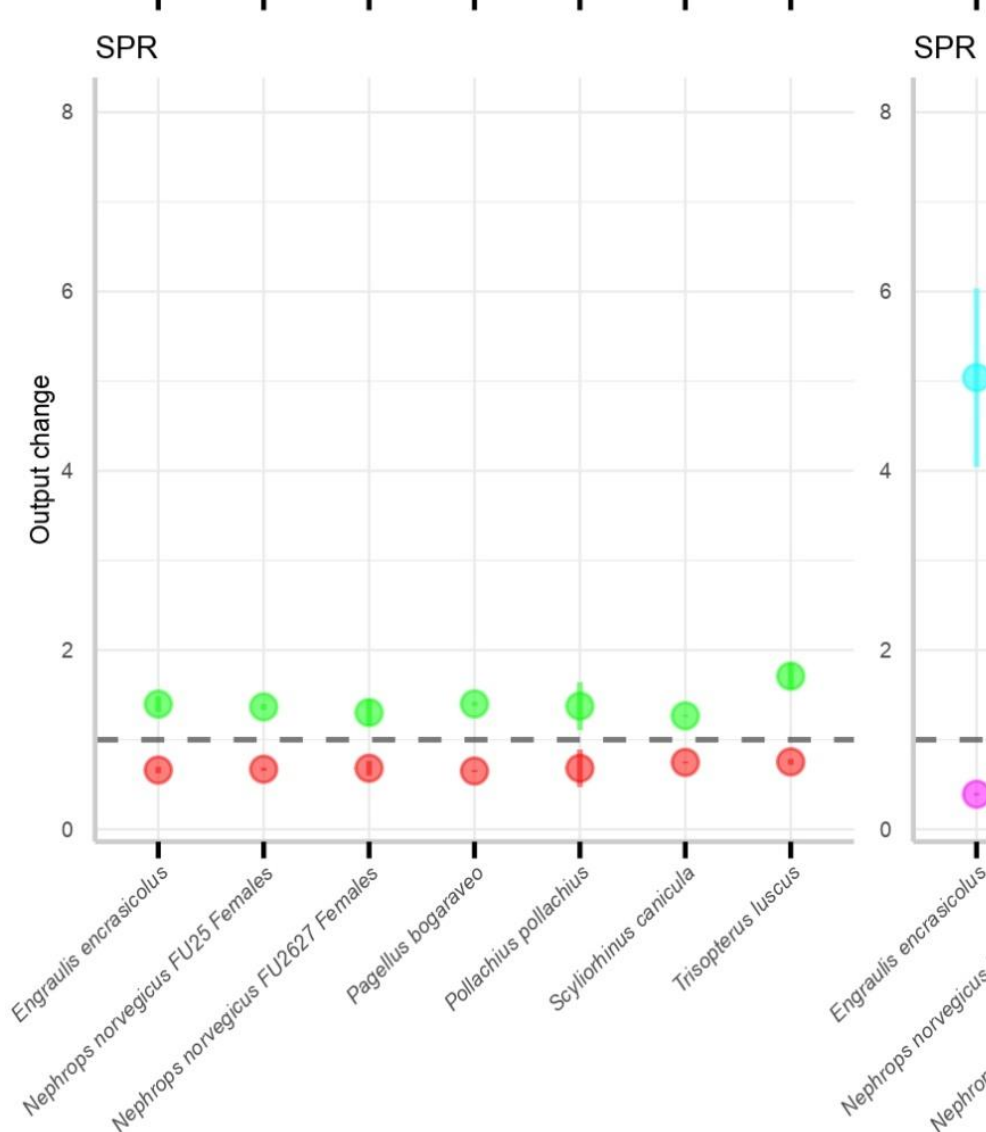

Species

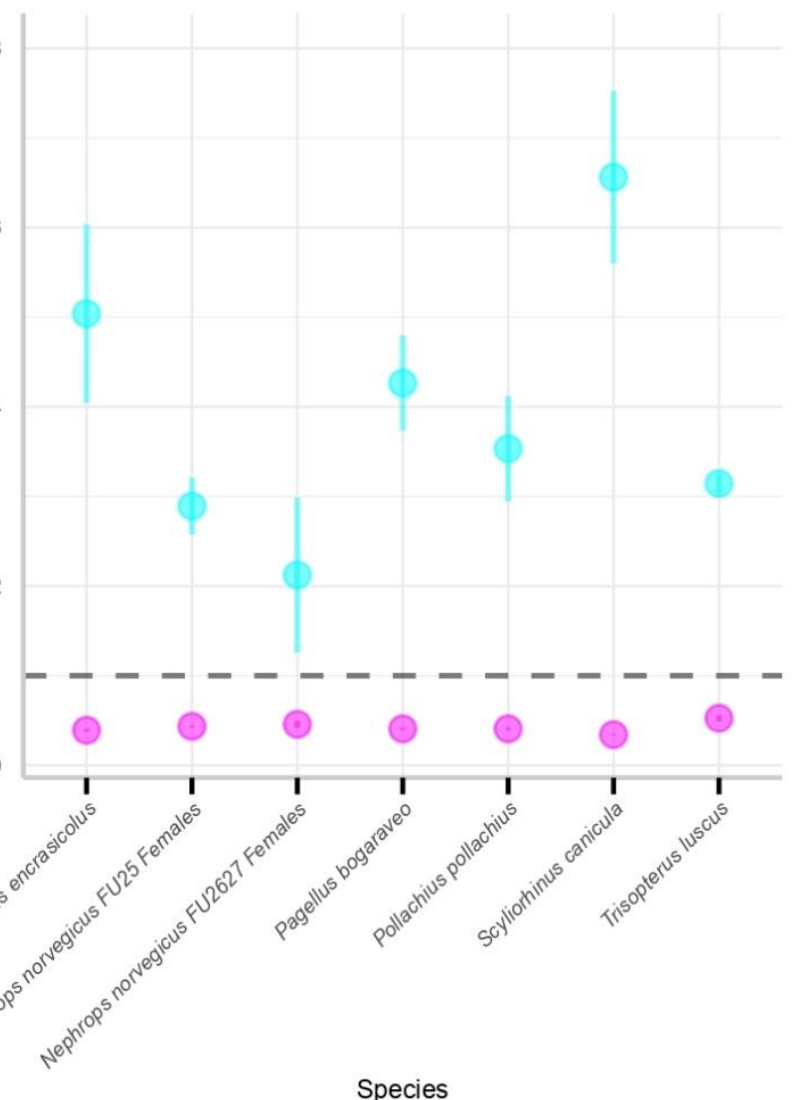


